\title{
The phylogenetic position of Artematopodidae (Coleoptera: Elateroidea), with description of the first two Eurypogon species from China
}

\author{
Robin Kundrata ${ }^{1,3}$, Milada Bocakova ${ }^{2}$, Ladislav Bocak ${ }^{1}$ \\ ${ }^{1}$ Department of Zoology, Faculty of Science, Palacky University, 17. listopadu 50, 779 00, Olomouc, Czech Republic \\ ${ }^{2}$ Department of Biology, Pedagogical Faculty, Palacky University, Purkrabska 2, 771 40, Olomouc, Czech Republic \\ ${ }^{3}$ E-mail: robin.kundrata@upol.cz.
}

Key words: mtDNA, rDNA, diversity, Elateriformia, new species, Palaearctic Region, phylogeny, taxonomy

\begin{abstract}
The Artematopodidae is a species-poor beetle family with contentious relationships to byrrhoid and elateroid families. Recent molecular phylogenetic analyses brought ambiguous results based on a single sequenced species. We investigated the taxonomic placement of Artematopodidae within Elateriformia using ribosomal $(18 \mathrm{~S}, 28 \mathrm{~S})$ and mitochondrial ( $r r n L$, coxl) molecular markers and three artematopodid species. Our analyses placed Artematopodidae close to Omethidae+Telegeusidae in a basal position of broadly defined Elateroidea. Additionally, we described the first artematopodid species from China - Eurypogon jaechi sp. nov. and E. heishuiensis sp. nov. These species are reported from mountains of Yunnan and can be easily distinguished from their Palaearctic congeners by their large bodies and metallic green elytra. They differ from each other by the shape of the pronotum, puncturation of the head and pronotum, the relative lengths of the antennomeres 3-5, and the morphology of the female genitalia. With respect to our findings, we discussed the phylogeny, diversity and distribution of the family Artematopodidae.
\end{abstract}

\section{Contents}

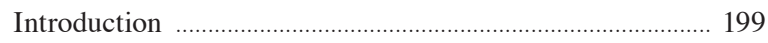

Material and methods ............................................................... 200

Molecular dataset and laboratory procedures ............... 200

Sequence handling, alignment and

phylogenetic analyses ....................................................... 200

Morphological taxonomy ................................................ 201

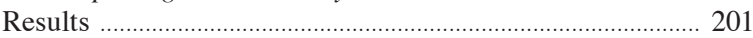

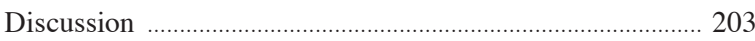

The phylogenetic position of Artematopodidae ............. 203

The zoogeography and diversity of the

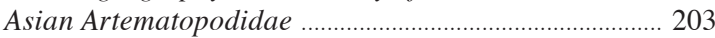

Acknowledgements ............................................................... 203

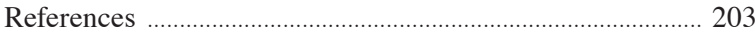

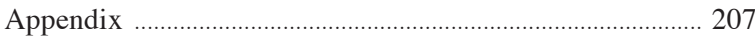

\section{Introduction}

The Artematopodidae is a species-poor beetle lineage currently classified in Elateroidea (Bouchard et al.,
2011). Altogether 66 extant species are placed in eight genera; six species were described from amber fossils (Hörnschemeyer, 1998; Lawrence, 2010). Artematopodids are characterized by the presence of paired carinae on the prosternum, connate abdominal ventrites, and an interlocking tongue-like process on the internal part of the elytral apex (Lawrence, 1995). Three subfamilies are recognized: Artematopodinae, which consist of Artematopodini, Ctesibiini and Macropogonini, monogeneric Allopogoniinae, and Electribiinae (Lawrence, 2005; Table S3).

The relationships of the Artematopodidae were contentious since their description by Lacordaire (1857) and even recent studies did not provide a robust phylogenetic hypothesis (Lawrence, 1995). The Artematopodidae were originally treated as a subgroup of the Dascillidae (e.g. Horn, 1880; Pic, 1914), mainly because of the similar general appearance and the presence of membranous lamellae on the ventral parts of the tarsomeres. Forbes (1926) placed them with Cerophytidae and Brachypsectridae among the basal Elateriformia. Using larval characters, Böving and Craighead (1931) classified them under the name Eurypogonidae into the Dryopoidea. Crowson (1955) formally followed their concept, but discussed the conflicting signal from adult morphology which suggests relationships to elateroid lineages. Later, he erected the superfamily Artematopoidea for the Artematopodidae, Brachypsectridae and Callirhipidae and discussed the relationships of the Artematopoidea with the Elateroidea and Cantharoidea (Crowson, 1973). Lawrence and Newton (1982) separated the Callirhipidae from the Artematopodidae. Lawrence (1988) merged the Artematopoidea, Elateroidea and Cantharoidea into a single broadly defined Elateroidea and inferred the Artematopodidae in variable positions: as sister to the Elateroidea sensu stricto (Crowson, 1955) + Brachypsectridae, sister to the Elateroidea sensu stricto + Brachypsectridae + some dryopoid lineages, 
Table 1. The list of newly sequenced taxa with GenBank accession and voucher numbers.

\begin{tabular}{|c|c|c|c|c|c|c|c|}
\hline Family & Genus/Species & $\begin{array}{l}\text { Geographical } \\
\text { origin }\end{array}$ & $\begin{array}{l}\text { Markers } \\
18 \mathrm{~S} \text { rDNA }\end{array}$ & 28S rDNA & 16S mtDNA & COI mtDNA & $\begin{array}{l}\text { Specimen } \\
\text { voucher }\end{array}$ \\
\hline Artematopodidae & Eurypogon japonicus & Japan, Nara Pref. & KF294761 & KF294767 & KF294755 & $\mathrm{KF} 2,4774$ & UPOL RK0091 \\
\hline Artematopodidae & Eurypogon hisamatsui & Japan, Tokushima Pref. & KF294762 & KF294768 & KF294756 & KF294775 & UPOL RK0128 \\
\hline Artematopodidae & Eurypogon brevipennis & Japan, Nagano Pref. & KF294763 & KF294769 & KF294757 & KF294776 & UPOL 001335 \\
\hline Omethidae & Drilonius sp. b & India, Kunchappanai & KF294764 & KF294770 & KF294758 & KF294777 & UPOL 001273 \\
\hline Omethidae & Drilonius sp.c & Philippines, Mindanao & KF294765 & KF294771 & KF294759 & KF294778 & UPOL RK0134 \\
\hline Throscidae & Trixagus meybohmi & Czech Republic, Moravia & KF294766 & KF294772 & KF294760 & KF294779 & UPOL RK0139 \\
\hline
\end{tabular}

or as a basal lineage of the Elateroidea. Beutel (1995) analyzed larval characters and found artematopodids regularly in monophyletic Elateroidea sensu Lawrence (1988) either close to the Elateridae, Cebrionidae and Cantharidae, or sister to the remaining Elateroidea. Lawrence et al. (1995) combined larval and adult characters and artematopodids either occupied a basal position in Elateroidea, were sister to the Elateroidea sensu stricto, formed a basal lineage in a clade containing the Elateroidea and several unrelated lineages, or were in an unresolved position within Elateriformia. The latest morphology-based phylogeny of Coleoptera (Lawrence et al., 2011) found Artematopodidae to be the basalmost lineage of Elateroidea.

No artematopodids were included in most molecular phylogenetic studies (Bocakova et al., 2007; Hunt et al., 2007; McKenna and Farrell, 2009; Kundrata and Bocak, 2011). Only Sagegami-Oba et al. (2007) used the artematopodid genus Eurypogon in their dataset of $18 \mathrm{~S}$ rDNA sequences and placed Eurypogon japonicus as a sister to the Heteroceridae in a wider clade of several byrrhoid families and Buprestidae. In the latest molecular phylogeny of the Coleoptera, Bocak et al. (2013) analyzed over 8000 terminals and Artematopodidae formed one of the basal lineages in Elateroidea, however, only two ribosomal loci (18S and 28S rDNA) represented Eurypogon japonicus in the five-marker dataset. Although the placement of the Artematopodidae in the Elateroidea is widely accepted (Cooper, 1991; Lawrence and Newton, 1995; Young, 2002; Lawrence, 2010; Bouchard et al., 2011), an underlying phylogenetic hypothesis is absent.

In this study, we expand available complete fourmarker data by newly sequenced representatives of basal elateroid lineages and three Eurypogon species to investigate the position of Artematopodidae within the elateriform series, and we describe two Eurypogon species, which represent the first record of the family in China.

\section{Material and methods}

\section{Molecular dataset and laboratory procedures}

The dataset contained 158 terminals. The newly sequenced 18S rDNA ( 1900 bp), 28S rDNA ( $\sim 700 \mathrm{bp})$, rrnL mtDNA ( $600 \mathrm{bp})$, and coxl mtDNA (723 bp) fragments were produced for three Eurypogon species (Artematopodidae), two species of Drilonius Kiesenwetter (Omethidae) and Trixagus meybohmi Leseigneur, 2005 (Throscidae; Table 1). Total DNA was extracted using the Wizard SV96 Purification System (Promega Corp., Madison, WI, USA). Further laboratory procedures, sequencing and primers were reported by Kundrata and Bocak (2011). The newly obtained data were merged with the dascilloid, byrrhoid and elateroid sequences used in recent molecular phylogenic studies of Elateroidea (Kundrata and Bocak, 2011; Table S1). Dascillus cervinus Linnaeus, 1758 (Dascillidae) as a member of basal Elateroidea (Bocak et al., 2013) was used as an outgroup. Only taxa with a complete set of four DNA markers were included in the dataset. GenBank accession numbers of sequences are listed in Tables 1 and S1. The classification follows Bouchard et al. (2011), with modifications made by Kundrata and Bocak (2011; for Elateridae and Omalisidae) and Janisova and Bocakova (2013; for Lampyridae: Ototretinae).

Sequence handling, alignment and phylogenetic analyses

Sequences were edited using Sequencher 4.7 (Gene Codes Corp., Ann Arbor, MI, USA). Protein-coding coxl sequences containing no indels were aligned by ClustalX 1.81 under default settings (Thompson et al., 1997). Additionally, for the alignment of rDNA and $r r n L$ mtDNA sequences we used either ClustalX or BlastAlign, which omits parts of the length varia- 
ble loops when reliable alignment cannot be inferred (Belshaw and Katzourakis, 2005). The concatenated datasets were analyzed under parsimony (MP), maximum likelihood (ML) and Bayesian algorithms. The MP analyses were carriı:d out using TNT 1.0 (Goloboff et al. 2003, 2008) with gaps treated as missing characters. The most parsimonious trees were found 50times and the bootstrap values were calculated from 1000 pseudoreplicates. Consensus trees were inferred from PAUP* 4.03b10 (Swofford, 2002). For $\mathrm{ML}$ and Bayesian analyses, the datasets were partitioned by genes and codon positions, yielding a total of six partitions. The Bayesian analyses were performed with Mr. Bayes 3.1.2 (Huelsenbeck and Ronquist, 2001). Four chains were run for $40.10^{6}$ generations, with trees sampled every 1,000 generations. The stationarity was detected in Tracer 1.5 (Rambaut and Drummond, 2007). For each analysis, the first $15 \%$ of trees were discarded as burn-in. The posterior probabilities were determined from the remaining trees. The ML analyses were conducted using RAxML 7.3.1 (Stamatakis, 2006) via the CIPRES web server (www.phylo.org; Miller et al., 2010). Branch supports were calculated using the rapid bootstrap algorithm (Stamatakis et al., 2008) with 1000 bootstrap iterations under the GTRCAT model.

\section{Morphological taxonomy}

The morphological study was based on adult semaphoronts. Genitalia were dissected, cleared in $10 \%$ aqueous solution of potassium hydroxide, dyed by chlorazol black and photographed using a digital camera mounted on a stereoscopic microscope. The following measurements were taken: BL-body length, measured from the fore margin of the head to the elytral apex; EL-elytral length; WHe-width of head including eyes; WH-width at humeri; PL-pronotal length at midline; PWA-pronotum width at anterior angles; PWP-pronotum width at posterior angles; Edist-minimum interocular distance in the frontal part of the cranium; Ediam-maximum eye diameter in lateral view; LV-length of valvifer; LC-length of coxit. A forward slash (/) separates different lines on a label. The species descriptions follow in general the recommendations of Ratcliffe (2013) and the morphological terminology follows those of Sakai (1982) and Lawrence (2010). The type material is deposited in the Naturhistorisches Museum Wien in Austria (NHMW).

\section{Results}

The 158-taxa concatenated BlastAlign and ClustalX datasets contained 4675 and 4330 homologous positions with 31.1 and $39.6 \%$ parsimony-informative characters, respectively. The numbers of homologous positions and constant, variable parsimony-informative and parsimony-uninformative characters for total matrices and individual markers shows the Table S2. The $r r n L$ and coxl mtDNA fragments contained considerably higher percentage of parsimony-informative characters than $18 \mathrm{~S}$ and $28 \mathrm{~S}$ rDNA. Base frequencies showed high AT levels in mitochondrial DNA (Table S2). The maximum uncorrected pairwise distances among investigated taxa varied between $8.9 \%$ for $18 \mathrm{~S}$ rDNA and $35.0 \%$ for coxl mtDNA (Table S2).

The phylogenetic analyses of data in the present constellation recovered Elateroidea sensu Lawrence and Newton (1995; i.e., including Artematopodidae) as a monophylum (Fig. 1). The concept of Elateroidea was supported by bootstrap values (BS) of $58-68 \%$ in ML analyses, less than 50\% in MP analyses, and 74$88 \%$ posterior probabilities (PP) in Bayesian analyses (Fig. 1). The Byrrhoidea was strongly supported in ML and Bayesian analyses of ClustalX alignment and weakly supported or paraphyletic in the remaining analyses. Artematopodidae were recovered in a basal position of the broadly defined Elateroidea; they formed an independent lineage in ML analysis of BlastAlign alignment (Fig. 1B; less than $50 \%$ BS) or they were sister to Omethidae + Telegeusidae in all remaining analyses (Fig. 1A; 58 and 100\% PP in Bayesian analyses of BlastAlign and ClustalX alignments, respectively, 97\% BS in ML analysis of ClustalX alignment, and less than 50\% BS in MP analyses). Elateroidea minus Artematopodidae + (Omethidae + Telegeusidae) obtained strong support in analyses of BlastAlign alignment (84\% BS, 100\% PP) and low to moderate support in analyses of ClustalW alignment (Fig. 1). Throscidae and Eucnemidae formed either independent lineages (4 analyses, Fig. 1B) or a single clade (2 analyses, Fig. 1A). The strongly supported clade consisting of two subclades Lycidae + Lampyridae + Cantharidae and Omalisidae + Phengodidae + Rhagophthalmidae + Elateridae was found in all analyses. All analyses recovered elateroid families monophyletic, only Bayesian analysis of BlastAlign alignment showed paraphyletic Elateridae including a clade Omalisidae + Phengodidae + Rhagophthalmidae (less than 50\% BS). All families but Omalisidae $(<50-92 \%$ BS, $99-100 \%$ PP) and Elateridae $(<50-75 \%$ BS, 94\% 


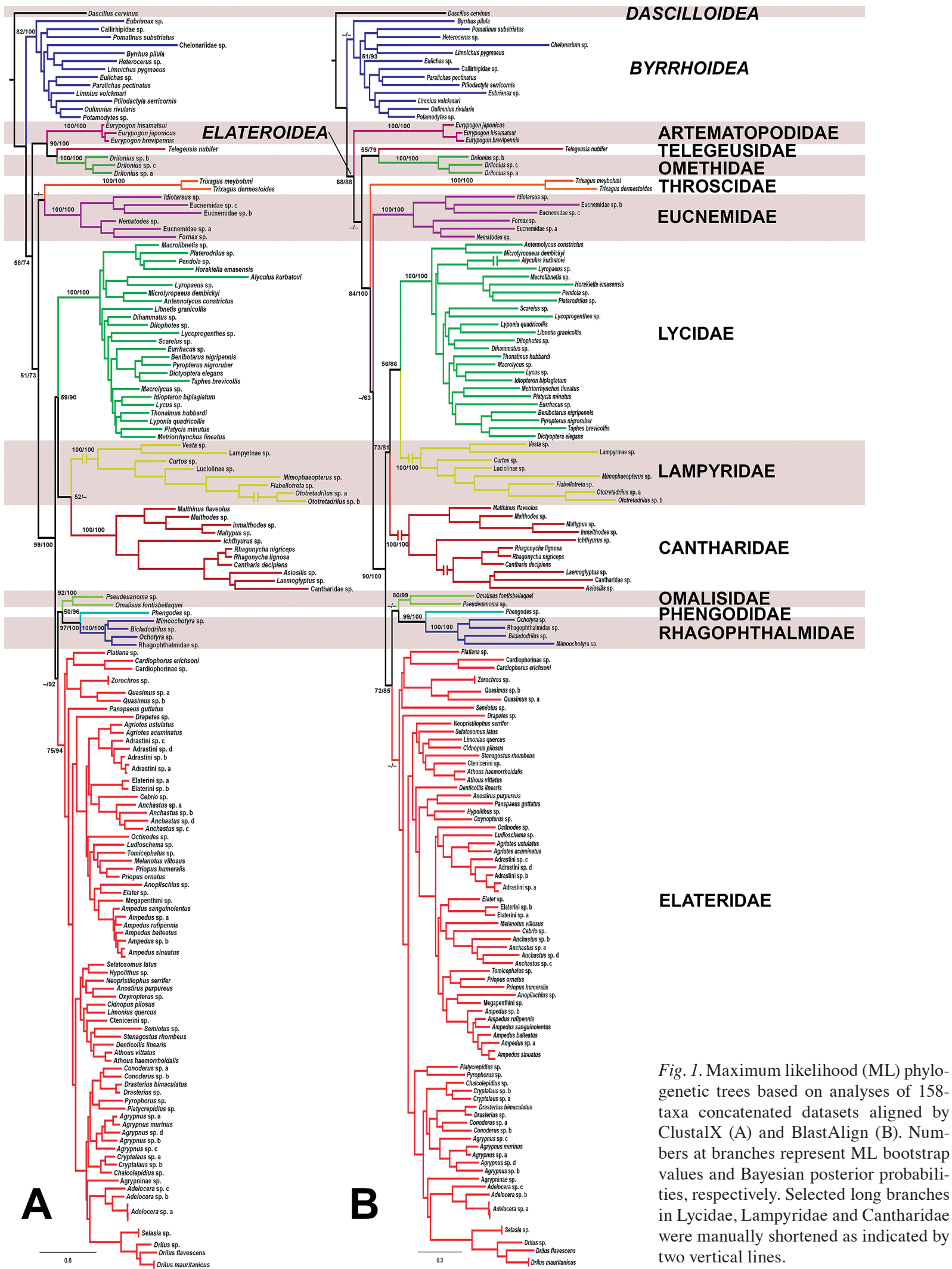


PP) obtained strong support in all analyses (92-100\% BS, $100 \%$ PP). Among Artematopodidae, the sistergroup relationship between Eurypogon hisamatsui Sakai, 1982 and E. brevipennis Sakai, 1982 obtained strong support in 4 analyses. In ML and Bayesian analyses of BlastAlign alignment, E. hisamatsui was found sister to E. japonicus Sakai, 1982 (65\% BS and 99\% $\mathrm{PP}$, respectively).

\section{Discussion}

\section{The phylogenetic position of Artematopodidae}

In this study, we combined ribosomal and mitochondrial DNA data to investigate the position of Artematopodidae. According to our analyses, Artematopodidae were never recovered near byrrhoid lineages as suggested by Sagegami-Oba et al. (2007; Fig. 1). The position of the Callirhipidae as a part of the Byrrhoidea and distant from Artematopodidae rejects Crowson's Artematopoidea (Crowson, 1973). The results placed artematopodids as a part of deep radiation of elateroid lineages in concordance with some recently published morphological and molecular analyses (e.g. Lawrence et al., 2011; Bocak et al., 2013; Fig. 1). Lawrence et al. (2011) recovered Artematopodidae as the basamost elateroid lineage and Bocak et al. (2013) inferred artematopodids as a sister to Elateroidea $\mathrm{mi}$ nus Telegeusidae and Omethidae. The basal position of Artematopodidae is also indicated by the fact that several species of Macropogonini feed on mosses (Lawrence, 2010). In our study, five out of six analyses revealed heretofore unknown sistergroup relationships of Artematopodidae and Omethidae + Telegeusidae (Fig. 1A). Only one analysis showed Artematopodidae sister to the remaining Elateroidea, but this topology was weakly supported (Fig. 1B). The Elateroidea except the three above mentioned basal lineages showed consistent support across the recent molecular analyses (Bocakova et al., 2007; Kundrata \& Bocak, 2011; this study; Fig. 1). On the other hand, although we can consider the placement of Artematopodidae in the basal radiation of the Elateroidea as well supported, their relationships to Omethidae and Telegeusidae remain unresolved (Bocak et al., 2013; this study; Fig. 1). The Brachypsectridae (supposed as the close relatives of Artematopodidae by e.g., Crowson, 1973) fixed for the DNA isolation and more data for Omethidae and Telegeusidae are needed for better understanding of the relationships among the basal elateroid lineages.
The zoogeography and diversity of the Asian Artematopodidae

Currently, eight extant artematopodid genera are defined (Lawrence, 2010; Table S3). Artematopus Perty is the most diverse genus (44 species), three genera contain 2-11 species, and four genera are monotypic. The artematopodids have the highest diversity in the New World (all genera and most species; Table S3), with Macropogon Motschulsky and Eurypogon distributed additionally in the Palaearctic Region. Three species of Macropogon occur in the Russian Far East, one Eurypogon species is known from southern Europe and seven Eurypogon species are distributed in East Asia (Sakai, 1982; Hörnschemeyer, 1998; this study). Eurypogon had contained only Nearctic species until Sakai (1982) described four species from Japan and one from Taiwan (Table S4), but no species was recorded from continental Asia. Here, we described two Eurypogon species from the geographically very distant area in Yunnan (Fig. 3; for the species descriptions see the Appendix). Hörnschemeyer (1998) considered the pattern of Artematopodidae distribution as relict. The distant isolated ranges of Chinese and Japanese species of Eurypogon suggest much more extensive distribution of this genus in the past. Of course, we cannot exclude further records of these rare beetles from further localities in China, but all Eurypogon occur in a low number of species in small isolated ranges across the World and they have not been reported from large regions between the known ranges (Tables S3 and S4).

\section{Acknowledgements}

We are grateful to Manfred Jäch (NHMW) who kindly provided us with the material of newly described species. This study was supported by following grants: GAČR P506/11/1757 (LB), internal grant of Faculty of Science, UP Olomouc (LB, RK), and EU-SYNTHESYS BE-TAF 2193 (RK). We also thank two anonymous reviewers for critical comments on an earlier version of the manuscript.

\section{References}

Belshaw R, Katzourakis A. 2005. BlastAlign: a program that uses blast to align problematic nucleotide sequences. Bioinformatics 21: 122-123. 
Beutel R. 1995. Phylogenetic analysis of Elateriformia (Coleoptera: Polyphaga) based on larval characters. Journal of Zoological Systematics and Evolutionary Research 33: 145-171.

Bocak L, Barton C, Crampton-Platt A, Chesters D, Ahrens D, Vogler AP. 2013. Building the Coleoptera tree-of-life for $>8000$ species: composition of public DNA data and fit with Linnaean classification. Systematic Entomology. doi: 10.1111/syen.12037.

Bocakova M, Bocak L, Hunt T, Vogler AP. 2007. Molecular phylogenetics of Elateriformia (Coleoptera): evolution of bioluminescence and neoteny. Cladistics 23: 477-496.

Bouchard P, Bousquet Y, Davies AE, Alonso-Zarazaga MA, Lawrence JF, Lyal CHC, Newton AF, Reid CAM, Schmitt M, Ślipiński SA, Smith ABT. 2011. Family-Group names in Coleoptera (Insecta). ZooKeys 88: 1-972.

Böving AG, Craighead FC. 1931. An illustrated synopsis of the principal larval forms of the order Coleoptera. Entomologica Americana 1: 1-351.

Cooper KW. 1991. Artematopodidae (Elateroidea). Pp. 407-409 in: Stehr FW, ed., Immature Insects. Volume 2. Dubuque, Iowa: Kendall/Hunt Publishing Company.

Crowson RA. 1955. The natural classification of the families of Coleoptera. London: Nathaniel Lloyd \& Co., Ltd.

Crowson RA. 1973. On a new superfamily Artematopoidea of polyphagan betles, with the definition of two new fossil genera from the Baltic amber. Journal of Natural History 7: 225-238.

Forbes WTM. 1926. The wing folding patterns of the Coleoptera. Journal of the New York Entomological Society 34: 1-139.

Goloboff PA, Farris JS, Nixon KC. 2003. TNT: Tree analysis using new technology. www.zmuc.dk/public/phylogeny/tnt.

Goloboff PA, Farris JS, Nixon KC. 2008. TNT, a free program for phylogenetic analysis. Cladistics 24: 774-786.

Horn GH. 1880. Synopsis of the Dascyllidae of the United States. Transactions of the American Entomological Society 8: 76-114.

Hörnschemeyer T. 1998. New species of Electribius Crowson 1973 (Coleoptera: Artematopodidae) from Baltic amber. Paläontologische Zeitschrift 72: 299-306.

Huelsenbeck JP, Ronquist F. 2001. MrBayes: Bayesian inference of phylogenetic trees. Bioinformatics 17: 754-755.

Hunt T, Bergsten J, Levkanicova Z, Papadopoulou A, St-John O, Wild R, Hammond PM, Ahrens D, Balke M, Caterino MS, Gómez-Zurita J, Ribera I, Barraclough TG, Bocakova M, Bocak L, Vogler AP. 2007. A comprehensive phylogeny of beetles reveals the evolutionary origins of a superradiation. Science 318: 1913-1916.

Janisova K, Bocakova M. 2013. Revision of the subfamily Ototretinae (Coleoptera: Lampyridae). Zoologischer Anzeiger 252: 1-19.

Kundrata R, Bocak L. 2011. The phylogeny and limits of Elateridae (Insecta, Coleoptera): is there a common tendency of click beetles to soft-bodiedness and neoteny? Zoologica Scripta 40: 364-378.

Lacordaire T. 1857. Histoire Naturelle des Insectes. Genera des Coléoptères. Tome IV. Librairie Encyclopédique de Roret, Paris.

Lawrence JF. 1988. Rhinorhipidae, a new beetle family from Australia, with comments on the phylogeny of the Elateriformia. Invertebrate Taxonomy 2: 1-53.
Lawrence JF. 1995. Electribius Crowson: alive and well in Mesoamerica, with notes on Ctesibius Champion and the classification of Artematopodidae. Pp. 411-431 in: Pakaluk J, Ślipiński SA, eds, Biology, Phylogeny, and Classification of Coleoptera: Papers Celebrating the 80th Birthday of Roy A. Crowson. Warszawa, Poland: Muzeum i Instytut Zoologii Polska Akademia Nauk.

Lawrence JF. 2005. Brevipogon, a new genus of North American Artematopodidae (Coleoptera), with a key to world genera. The Coleopterists Bulletin 59: 223-236.

Lawrence JF. 2010. 4.2. Artematopodidae Lacordaire, 1857. Pp. 42-47 in: Leschen RAB, Beutel RG, Lawrence JF, vol. eds, Coleoptera, Beetles; Volume 2: Morphology and Systematics (Elateroidea, Bostrichiformia, Cucujiformia partim). In: Kristensen NP, Beutel RG, eds, Handbook of Zoology, Arthropoda: Insecta. Berlin/New York: Walter de Gruyter $\mathrm{GmbH} \& \mathrm{Co}$. KG.

Lawrence JF, Newton AF. 1982. Evolution and classification of beetles. Annual Review of Ecology and Systematics 13: 261290.

Lawrence JF, Newton AF. 1995. Families and subfamilies of Coleoptera (with selected genera, notes, references and data on family-group names). Pp. 779-1006 in: Pakaluk J, Ślipiński SA, eds, Biology, Phylogeny, and Classification of Coleoptera: Papers Celebrating the 80th Birthday of Roy A. Crowson. Warszawa, Poland: Muzeum i Instytut Zoologii Polska Akademia Nauk.

Lawrence JF, Nikitsky NB, Kirejtshuk AG. 1995. Phylogenetic position of Decliniidae (Coleoptera: Scirtoidea) and comments on the classification of Elateriformia (sensu lato). Pp. 375-410. In: Pakaluk J, Ślipiński SA, eds, Biology, Phylogeny, and Classification of Coleoptera: Papers Celebrating the 80th Birthday of Roy A. Crowson. Warszawa, Poland: Muzeum i Instytut Zoologii Polska Akademia Nauk.

Lawrence JF, Ślipiński SA, Seago AE, Thayer MK, Newton AF, Marvaldi AE. 2011. Phylogeny of the Coleoptera based on morphological characters of adults and larvae. Annales Zoologici 61: 1-217.

Leseigneur L. 2005. Description de Trixagus meybohmi n. sp. et note sur la morphologie des Trixagus du groupe carinifrons (Coleoptera, Throscidae). Bulletin de la Société entomologique de France 110: 89-96.

McKenna DD, Farrell BD. 2009. Beetles (Coleoptera). Pp. 278289 in: Hedges SB, Kumar S, eds, The Timetree of Life. New York: Oxford University Press.

Miller MA, Pfeiffer W, Schwartz T. 2010. Creating the CIPRES Science Gateway for inference of large phylogenetic trees. Pp. 1-8 in: Proceedings of the Gateway Computing Environments Workshop (GCE), 14 Nov. 2010, New Orleans, LA.

Pic M. 1914. Dascillidae, Helodidae, Eucinetidae. In: Schenkling S, ed., Coleopterorum Catalogus. Pars 58. Berlin, W. Junk, 65 pp.

Rambaut A, Drummond AJ. 2007. Tracer version 1.5. Institute of Evolutionary Biology University of Edinburgh, Edinburgh.

Ratcliffe, BC. 2013. Best writing and curatorial practices for describing a new species of beetle: A primer. The Coleopterists Bulletin 67: 107-113.

Sagegami-Oba R, Takahashi N, Oba Y. 2007. The evolutionary process of bioluminescence and aposematism in cantharoid beetles (Coleoptera: Elateroidea) inferred by the analysis of 18S ribosomal DNA. Gene 400: 104-113. 
Sakai M. 1982. Occurence of the genus Eurypogon Motschulsky in Japan and Taiwan (Coleoptera: Artematopidae). Transactions of the Shikoku Entomological Society 16: 51-61.

Stamatakis A. 2006. RAxML-VI-HPC: Maximum likelihoodbased phylogenetic analyses with thousands of taxa and mixed models. Bioinformatics 22: 2688-2690.

Stamatakis A, Hoover P, Rougemont J. 2008. A Rapid Bootstrap Algorithm for the RAxML Web Servers. Systematic Biology 57: 758-771.

Swofford DL. 2002. PAUP*: Phylogenetic Analysis Using Parsimony (*and other Methods), v.4.0b10. Sinauer Associates, Sunderland, MA.

Thompson JD, Gibson TJ, Plewniak F, Jeanmougin F, Higgins DG. 1997. The CLUSTAL_X windows interface: flexible strategies for multiple sequence alignment aided by quality analysis tools. Nucleic Acids Research 25: 4876-4882.

Young DK. 2002. Artematopodidae Lacordaire 1857. Pp. 146147. In: Arnett RH, Thomas MC, Skelley PE, Frank JH, eds, American Beetles. Volume 2: Polyphaga: Scarabaeoidea through Curculionoidea. Boca Raton, Florida, USA, CRC Press LLC.

Received: 26 June 2013

Revised and accepted: 5 November 2013

Published online: 20 December 2013

Editor: H. de Jong

\section{On-line Supplementary Information}

Table S1. The list of previously published sequences used in the dataset (Bocakova et al., 2007; Kundrata and Bocak 2011).

Table S2. Numbers of characters, base frequencies and maximum uncorrected pairwise distances.

Table S3. List of artematopodid genera, with geographical distributions.

Table S4. List of described species of the genus Eurypogon Motschulsky, with geographical distributions. 

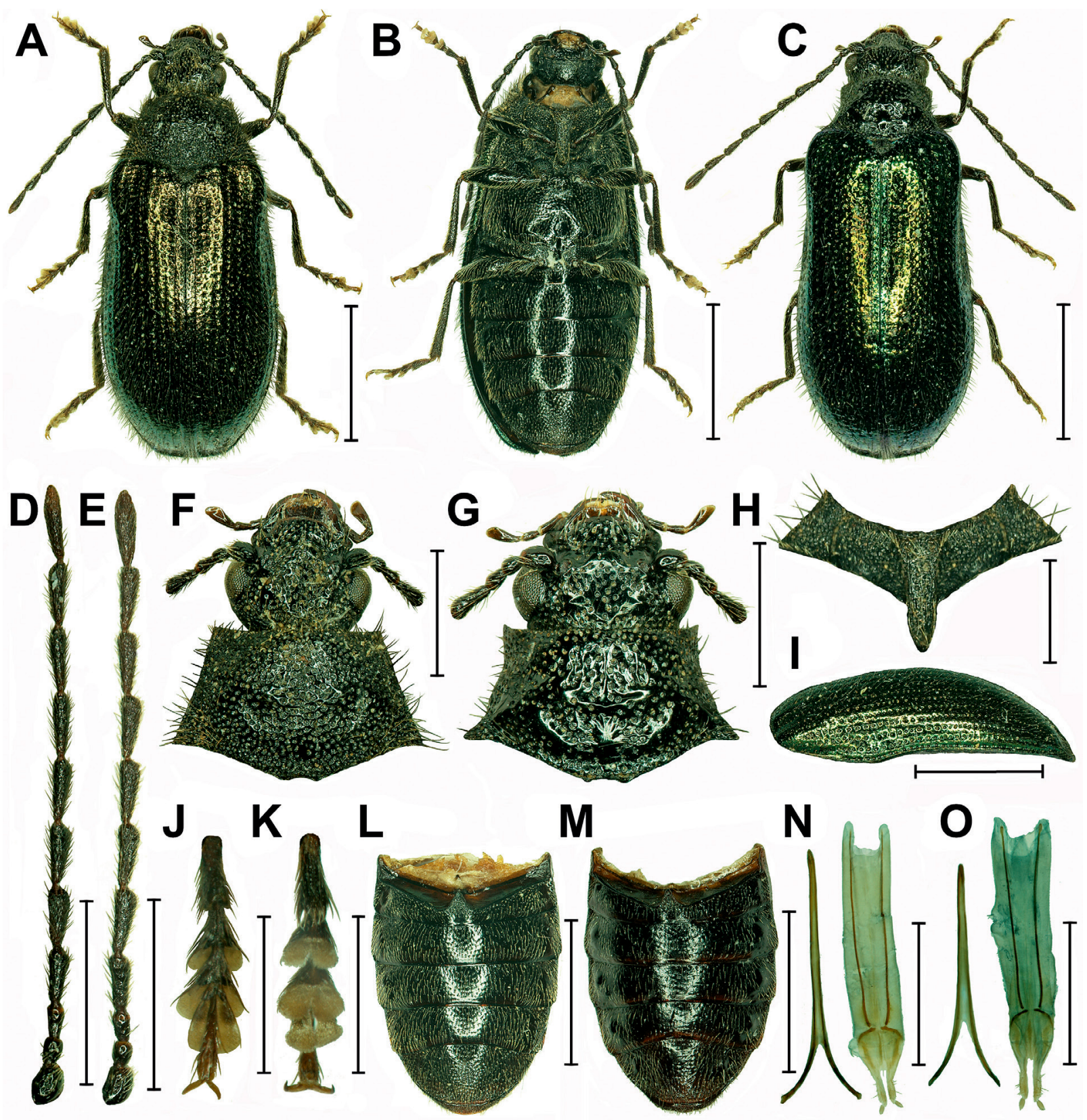

Fig. 2. Habitus of Eurypogon spp.: (A) E. jaechi sp. nov., dorsal habitus, (B) ventral habitus, (C) E. heishuiensis sp. nov., dorsal habitus; antenna: (D) E. jaechi sp. nov., (E) E. heishuiensis sp. nov.; pronotum: (F) E. jaechi sp. nov., (G) E. heishuiensis sp. nov.; E. jaechi sp. nov.: (H) prosternum, (I) elytron, dorsolaterally, (J) tarsomeres, dorsally, (K) ventrally; abdominal ventrites: (L) E. jaechi sp. nov., (M) E. heishuiensis sp. nov.; spiculum ventrale and valvifer with coxites: (N) E. jaechi sp. nov., (O) E. heishuiensis sp. nov. Scale bars: 2 mm (Figs 2-4, 10, 13-14), 1 mm (Figs 5-8, 15-16), 0.5 mm (Figs 9, 11-12). 


\section{Appendix}

\section{Systematics}

Eurypogon Motschulsky, 1859

Diagnosis. Within Macropogonini, Eurypogon can be easily distinguished from Macropogon by subequal antennomeres 4 and 5 which are each considerably longer than antennomere 3 (in Macroprogon antennomere 5 is 2.5 times longer than antennomere 4 which is subequal to antennomere 3), basal pro- and mesotarsomeres without ctenidium and larva without distinct paired urogomphi on the $9^{\text {th }}$ abdominal tergite (Crowson, 1973; Lawrence, 2005). The East Palaearctic Eurypogon species were described in detail by Sakai (1982).

Eurypogon jaechi sp. nov.

Fig. 2A-B, D, F, H-L, N

Type material. Holotype, 1 female, "China Yunnan, 1.19.VII. / HEISHUI, $35 \mathrm{~km} \mathrm{~N}$ Lijiang / $27^{\circ} 13^{\prime} \mathrm{N} 100^{\circ}$ 19'E / E. Jendek leg. 1992" (NHMW).

Diagnosis. Eurypogon jaechi sp. nov. and E. heishuiensis sp. nov. are the only known artematopodids from continental Asia and can be easily distinguished from their Japanese and Taiwanese congeners by larger body and metallic green coloration of elytra (species from Japan and Taiwan are uniformly black). E. jaechi sp. nov. differs from similar E. heishuiensis sp. nov. by the following characters: dull metallic elytral coloration, slightly wider body (Fig. 2A, C), pronotum with less concave sides and less prominent hind angles, larger and denser punctures on head and pronotum (Fig. 2F$\mathrm{G}$ ), different relative lengths of antennomeres 3-5 (Fig. 2D-E), less prominent elevations near lateral sides of abdomen (Fig. 2L-M), and higher valvifer/coxit length ratio (Fig. 2N-O).

Description. Female. Body $6.1 \mathrm{~mm}$ long, 2.7 times as long as wide at humeri (Fig. 2A-B). Body coloration grey to black; elytra metallic dark green, moderately shiny; legs dark brown, tarsal lamellae yellow. Entire body densely covered by suberect or erect pubescence. Head deflexed (i.e., there is a deflexion point between frons and clypeus; anterior part of cranium is declined), cranium irregularly covered with large punctures; punctures circular to oval, sparser and variable in size on clypeus, interstices smooth, narrow, up to width of puncture diameter on clypeus; anterior clypeal margin slightly convex (Fig. 2F). Eyes protuberant; interocular distance 2.0 times eye diameter in dorsal view. Maxil- lary palpi almost 2 times longer than labial palpi, apical palpomere slender, widest at apex (Fig. 2F). Antennae 11-segmented, reaching second third of elytral length, covered by suberect hairs; antennomere 1 pear-shaped, antennomeres 2-3 simple, their combined lengths slightly longer than length of antennomere 4; antennomeres 4-10 slightly serrate, subequal in length, apical antennomere simple (Fig. 2D). Pronotum pentagonal, moderately convex, anterior edge simple, almost straight, lateral margins moderately straight, posterior margin evenly rounded, slightly sinuate in middle part. Anterior angles almost rectangular; posterior angles acute (Fig. 2F); surface with large, ovoid, moderately deep punctures, with smooth, very narrow interstices; shiny, covered by erected, long setae, mainly at margins. Prosternum transverse, with paired longitudinal ridges in front of coxae, continuing as sides of prosternal process; prosternal process overlapping mesoventrite (Fig. 2B, H). Scutellum flat, triangle-shaped. Elytra moderately shiny, sinuate behind humeri, widest at third fourth, finely and deeply punctate with distinct puncture rows (Fig. 2A, I); covered by suberect pubescence; elytral margins strenghtened, particularly apically. Legs slender, femora widest mesally, tibiae elongate, bearing spurs apically. Tarsomeres 2-4 ventrally with deeply bifid lamellae; lamella of tarsomere 3 largest; penultimate tarsomere shortest, ultimate tarsomere slender, longest; claws slightly curved (Fig. 2J, K). Abdomen short, wellsclerotized, finely and moderately deeply punctate, with suberect pubescence. All ventrites connate, each ventrite with a circular smooth elevation near lateral edges (Fig. 2L). Spiculum ventrale long, slender (Fig. 2N). Female genitalia with long and slender valvifer; valvifer 2.5 times longer than coxit (Fig. $2 \mathrm{~N}$ ).

Measurements. BL $6.1 \mathrm{~mm}$, EL $4.7 \mathrm{~mm}$, WHe 1.1 mm, WHum $2.2 \mathrm{~mm}$, PL $1.1 \mathrm{~mm}$, PWA $1.2 \mathrm{~mm}$, PWP $1.9 \mathrm{~mm}$, Edist $0.8 \mathrm{~mm}$, Ediam $0.4 \mathrm{~mm}, \mathrm{LV} 1.4 \mathrm{~mm}, \mathrm{LC}$ $0.6 \mathrm{~mm}$.

Distribution. This species is known only from the type locality in Yunnan, China (Fig. 3).

Etymology. The species is dedicated to Manfred Jäch (NHMW) who provided us with the type material.

Eurypogon heishuiensis sp. nov.

Fig. 2C, E, G, M, O

Type material. Holotype, 1 female, "China Yunnan, 1.19.VII. / HEISHUI, $35 \mathrm{~km}$ N Lijiang / $27^{\circ} 13^{\prime} \mathrm{N} 100^{\circ}$ 19'E / E. Jendek leg. 1992” (NHMW). 


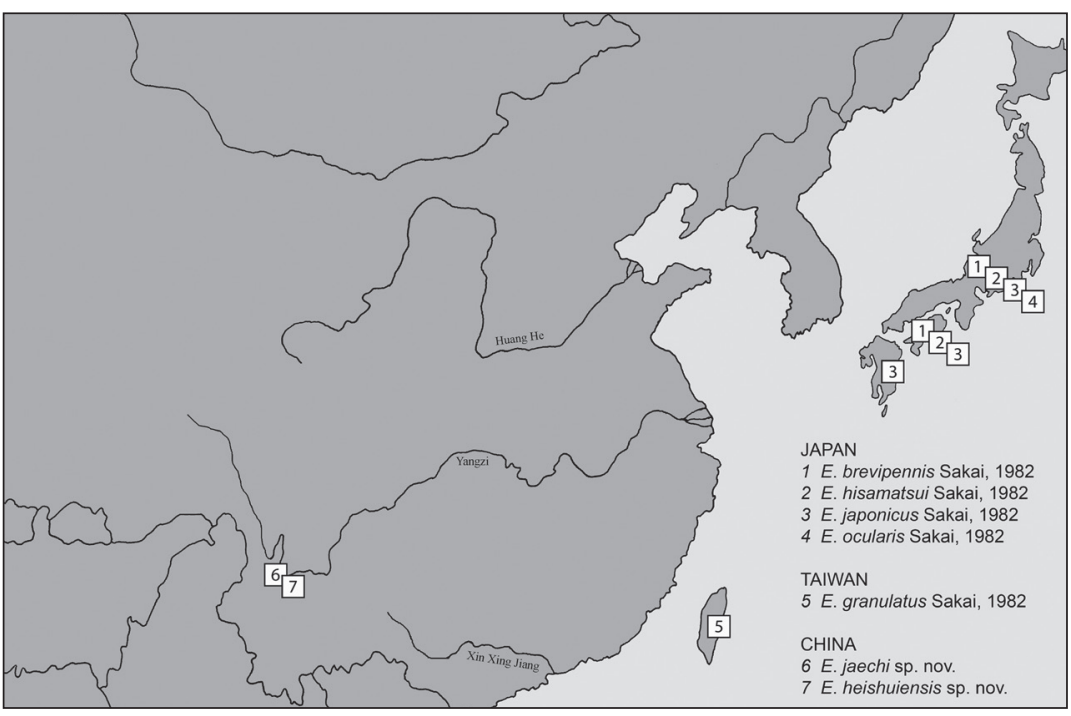

Fig. 3. The distribution of the genus Eurypogon in East Palaearctic Region.
Diagnosis. E. heishuiensis sp. nov. differs from $E$. jaechi sp. nov. by more metallic elytral coloration, narrower body (Fig. 2A, C), more concave pronotal sides and more prominent pronotal hind angles, smaller and sparser punctures on head and pronotum (Fig. 2F-G), different relative lengths of antennomeres 3-5 (Fig. 2D-E), more prominent elevations near lateral sides of abdomen (Fig. 2L-M), and lower valvifer/coxit length ratio (Fig. 2N-O).

Description. Body $6.1 \mathrm{~mm}$ long, 2.9 times as long as wide at humeri (Fig. 2C). Body coloration grey to black; elytra strongly metallic green, shiny; legs dark brown, tarsal lamellae yellow. Head irregularly and sparsely covered with moderately large punctures. Eyes protuberant; interocular distance 1.9 times eye diameter. Antennae with antennomere 1 pear-shaped, antennomeres 2-3 simple, minute, their combined lengths subequal to length of antennomere 4; antennomeres 4-10 slightly serrate; antennomere 5 slightly longer than antennomere 4; antennomeres 6-10 slightly short- er than antennomere 5, subequal in length; apical antennomere simple (Fig. 2E). Pronotum with anterior edge almost straight, lateral margins slightly concave, posterior margin evenly rounded, slightly sinuate in middle part. Anterior angles deflexed, almost rectangular; posterior angles acute (Fig. 2G); surface of disc shiny, with moderately large, ovoid punctures. Elytra shiny, finely and deeply punctate with distinct puncture rows (Fig. 2C). Abdominal ventrites with apparent circular smooth elevation near lateral edges (Fig. 2M). Spiculum ventrale moderately long, slender (Fig. 2O; valvifer 2.0 times longer than coxit (Fig. 2O).

Measurements. BL $6.1 \mathrm{~mm}$, EL $4.7 \mathrm{~mm}$, WHe 1.2 mm, WHum $2.1 \mathrm{~mm}$, PL $1.0 \mathrm{~mm}$, PWA $1.2 \mathrm{~mm}$, PWP $1.8 \mathrm{~mm}$, Edist $0.8 \mathrm{~mm}$, Ediam $0.4 \mathrm{~mm}, \mathrm{LV} 1.2 \mathrm{~mm}, \mathrm{LC}$ $0.6 \mathrm{~mm}$.

Distribution. This species is known only from the type locality in Yunnan, China (Fig. 3).

Etymology. The species name heishuiensis refers to the type locality of the species. 


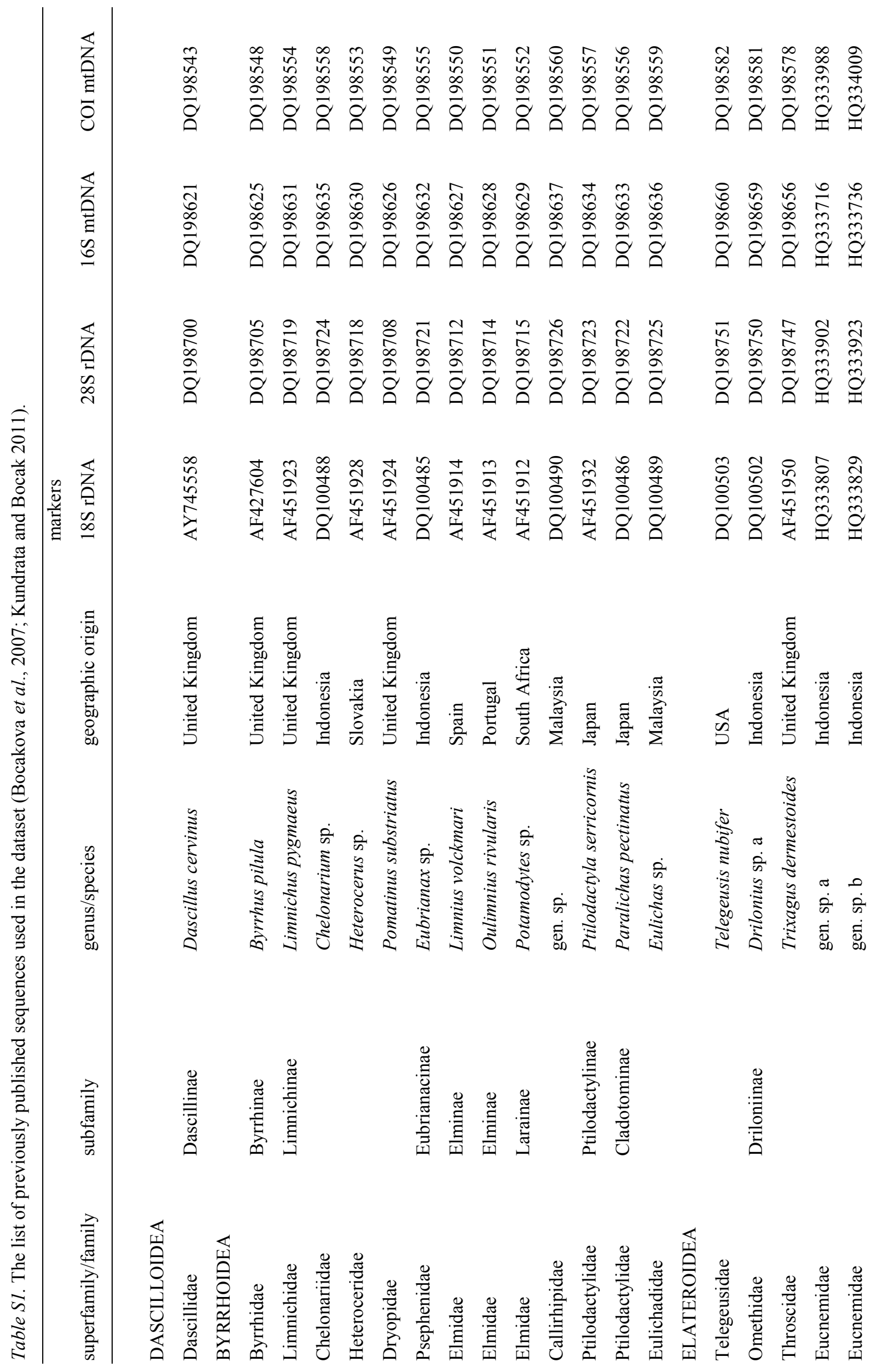




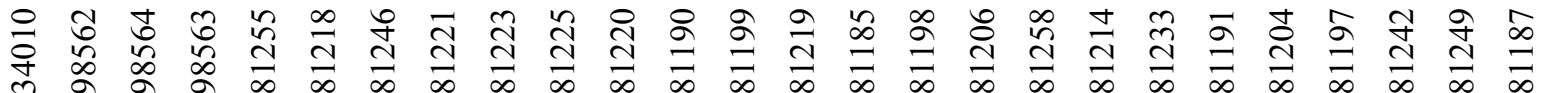

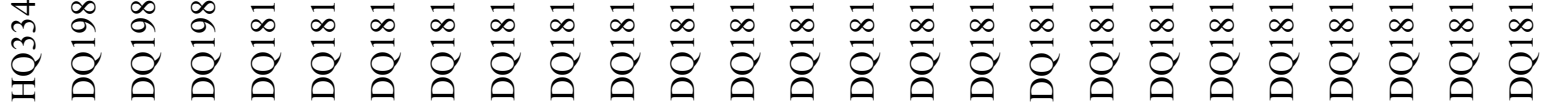

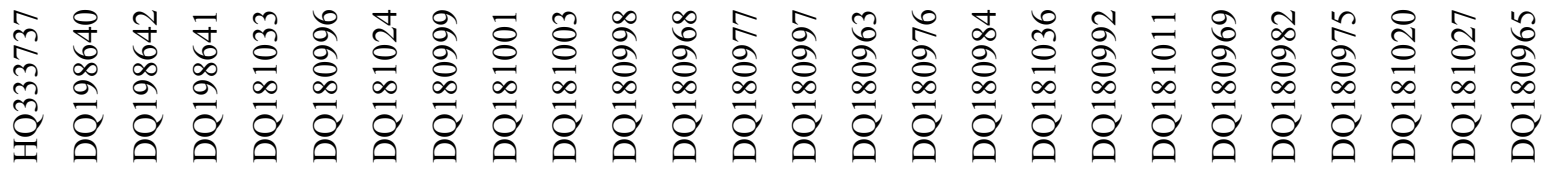

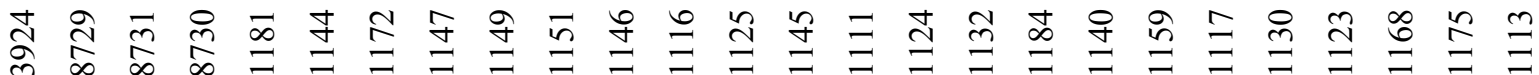

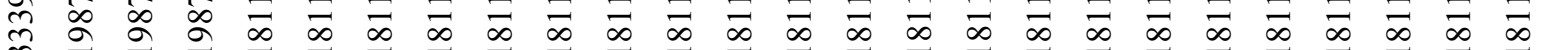

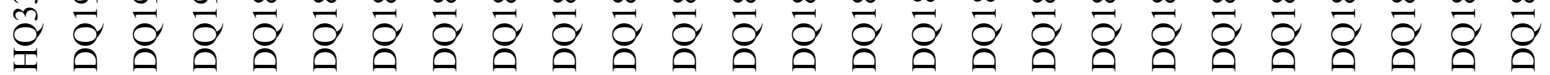

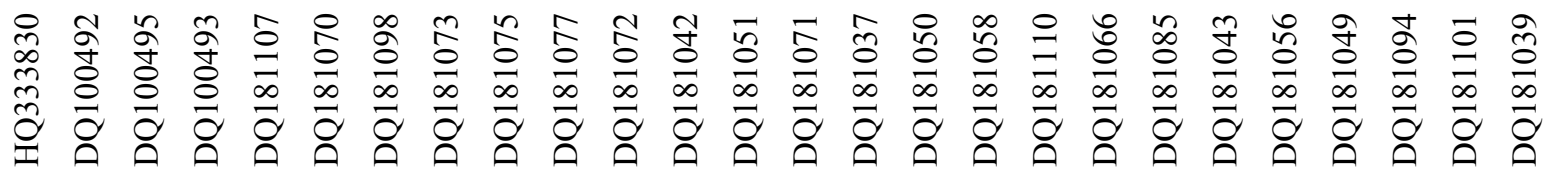

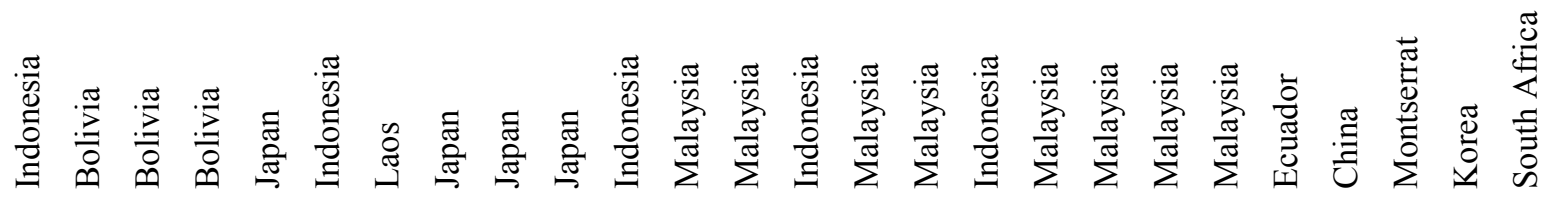

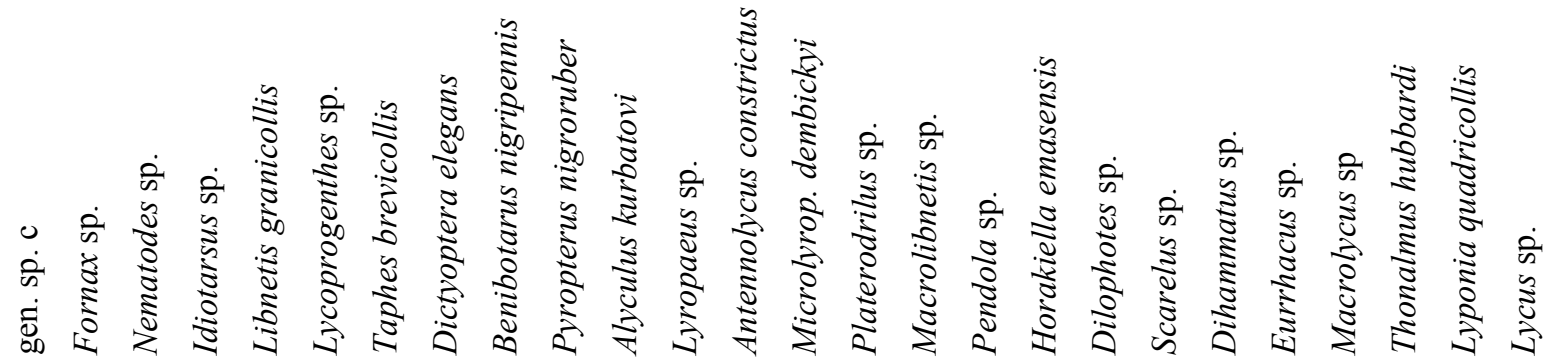

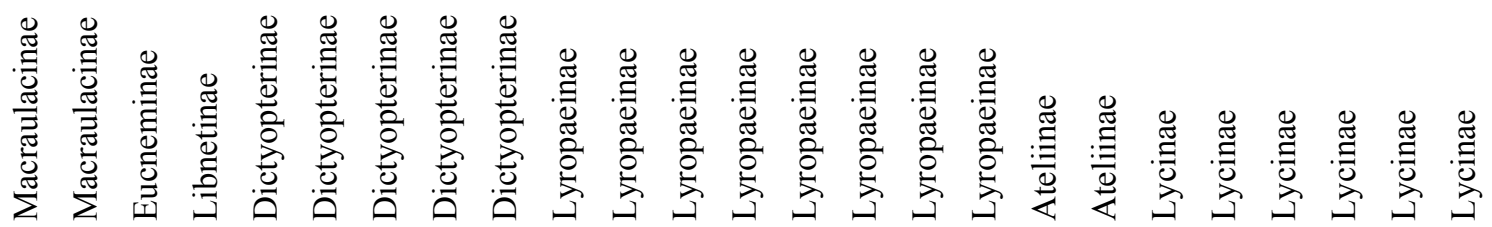

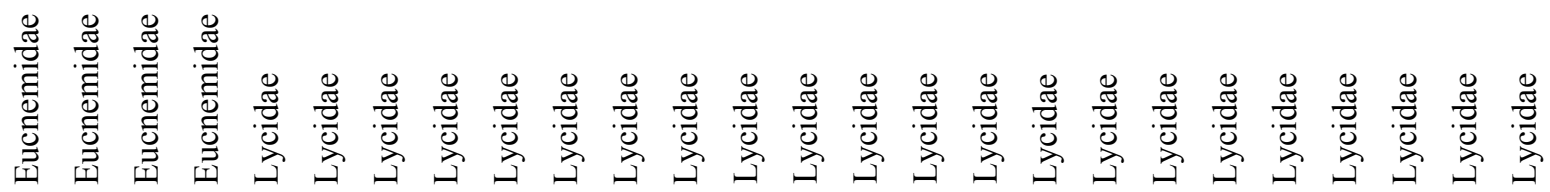




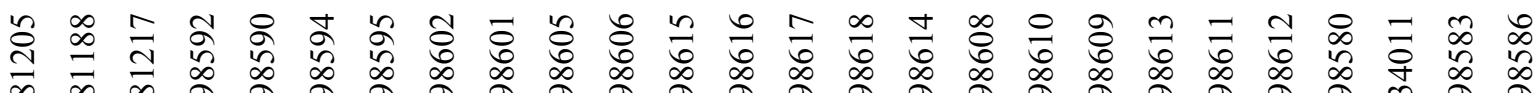

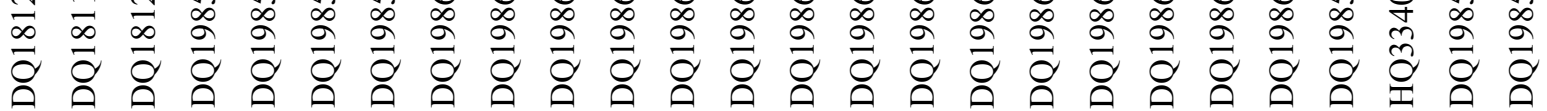

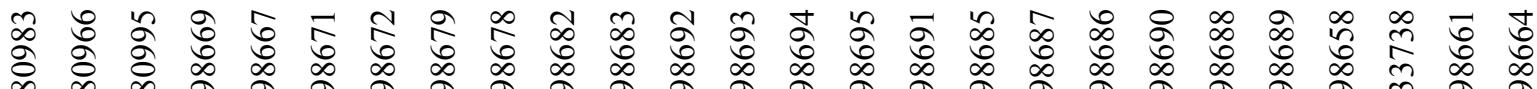

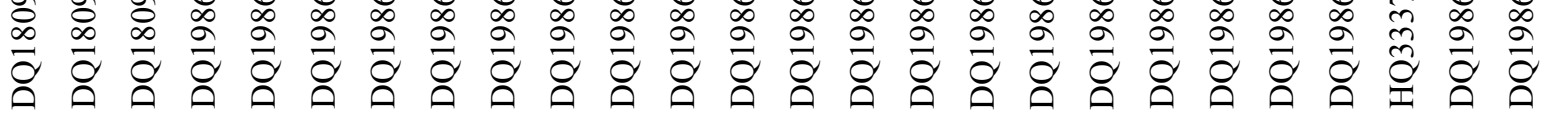

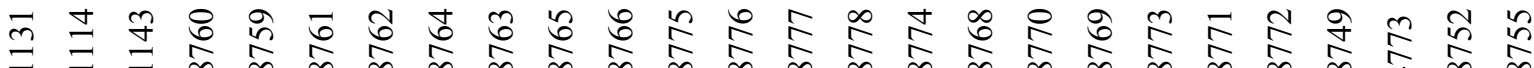

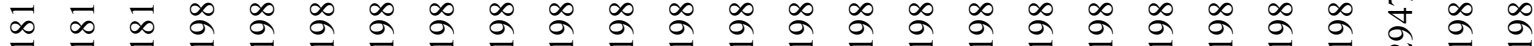

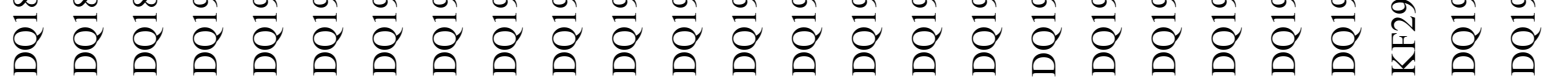

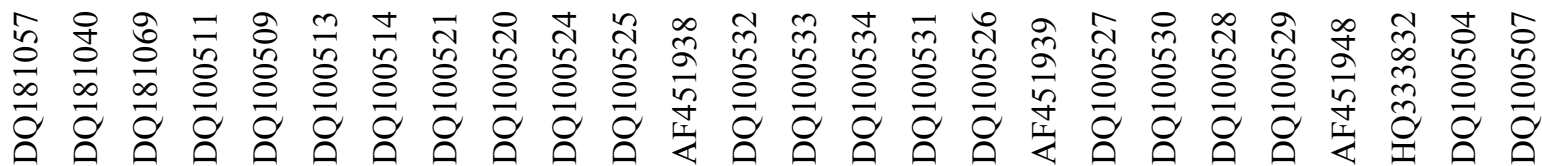

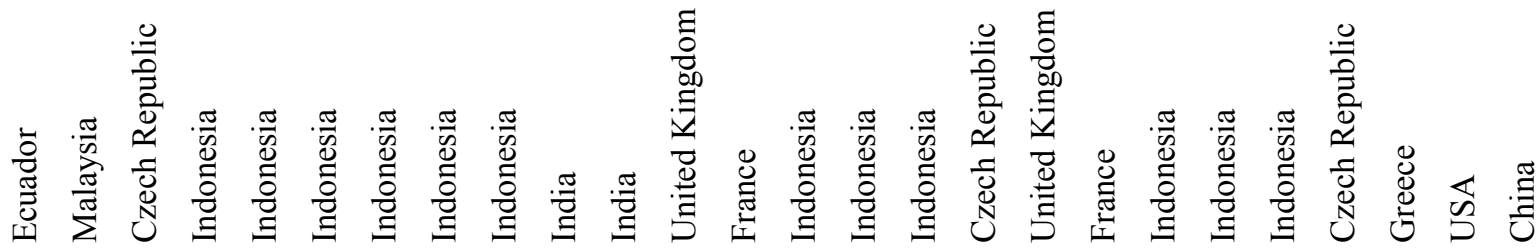

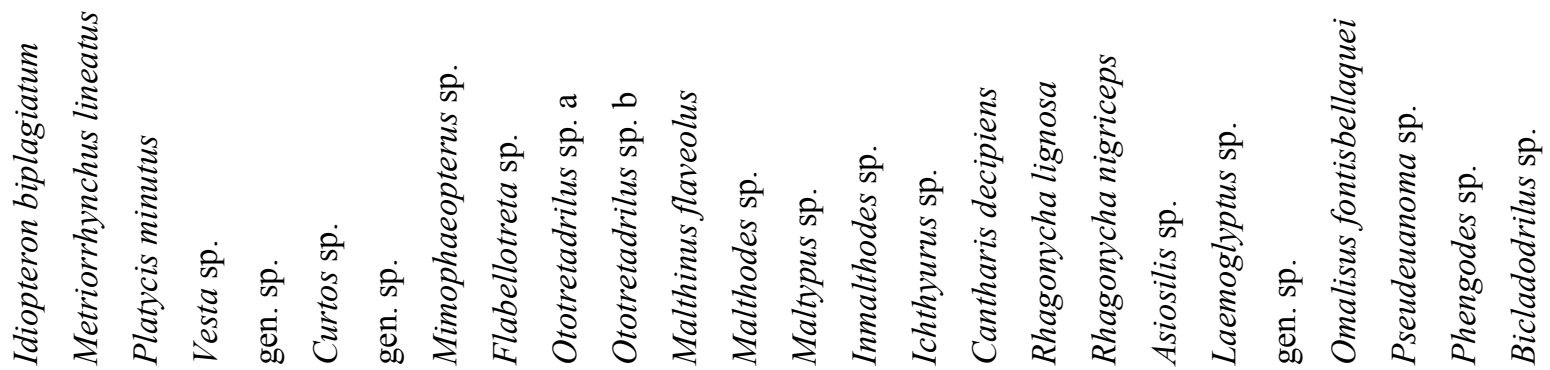

芯

总 


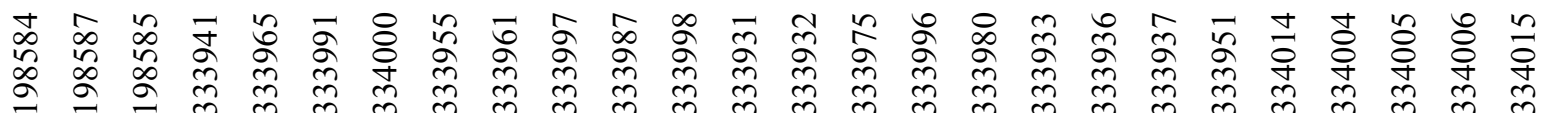

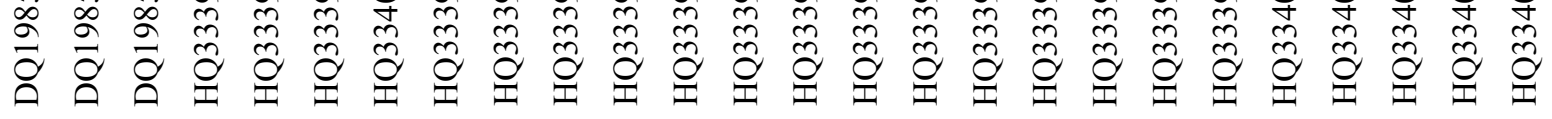

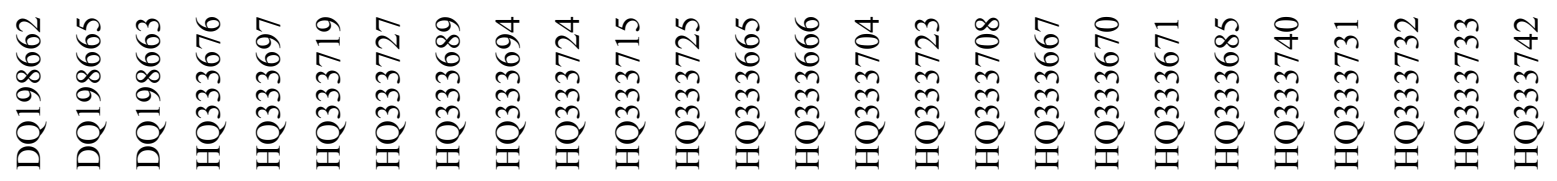

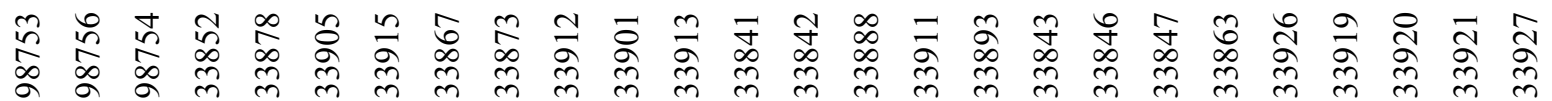

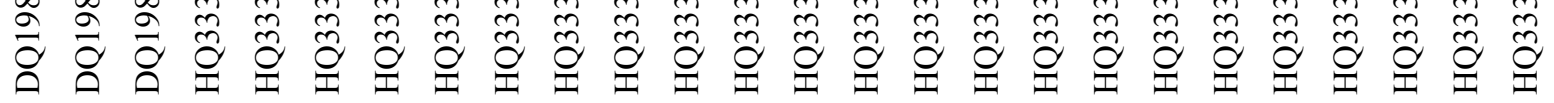

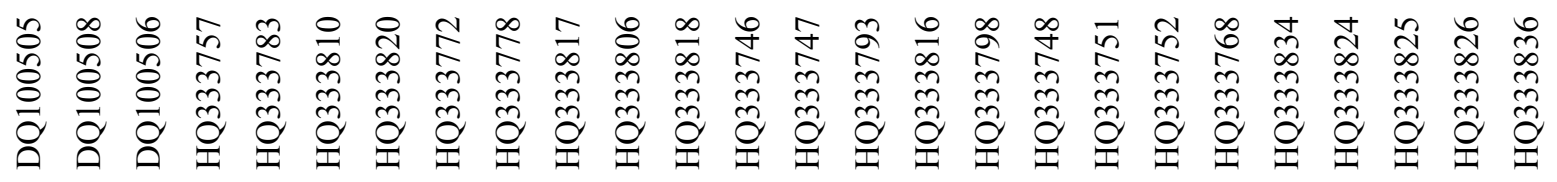

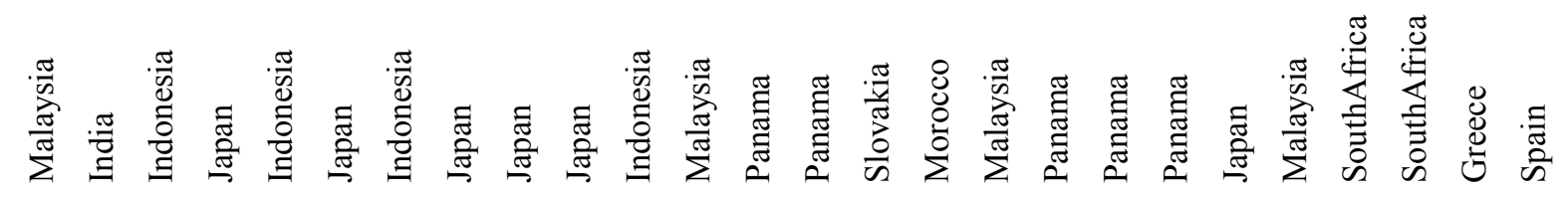

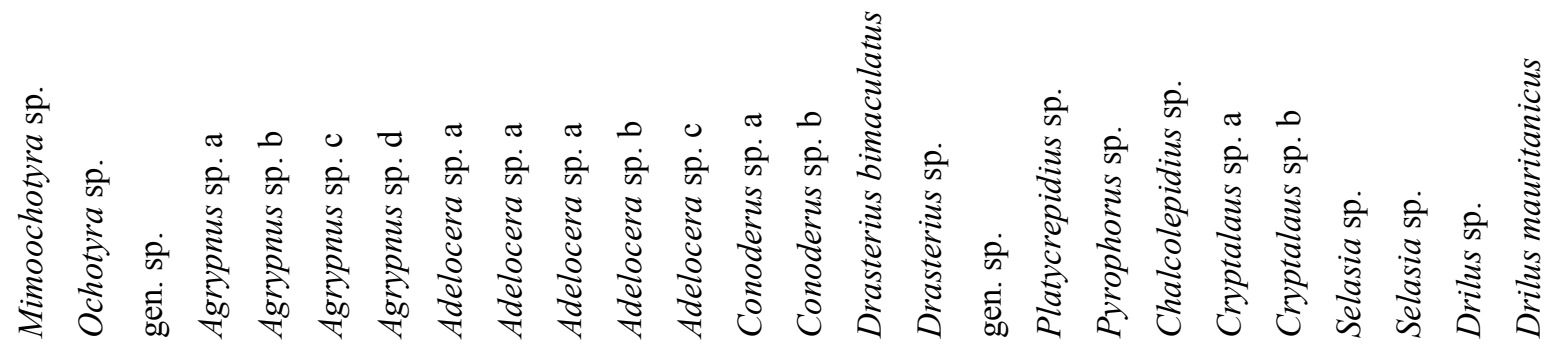

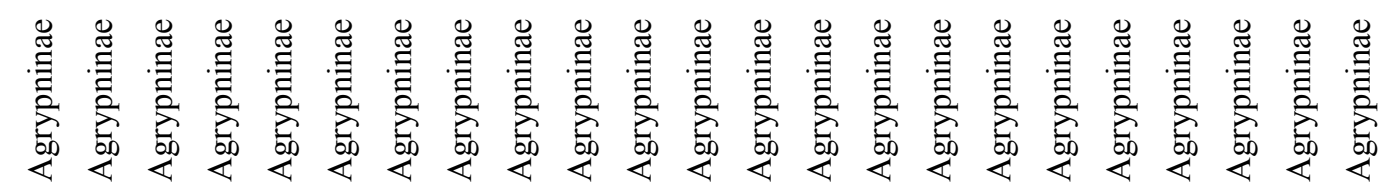

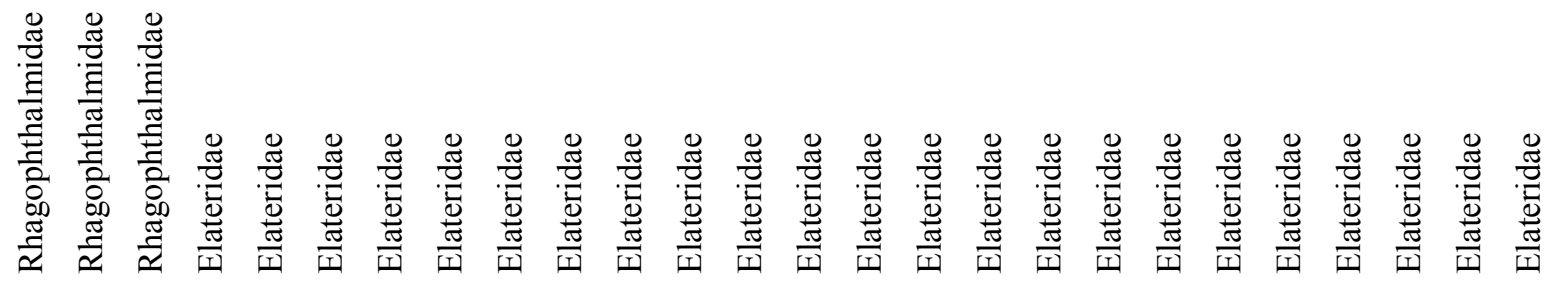




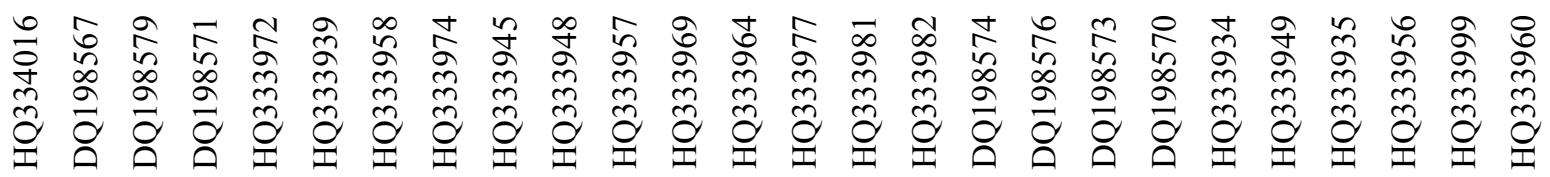

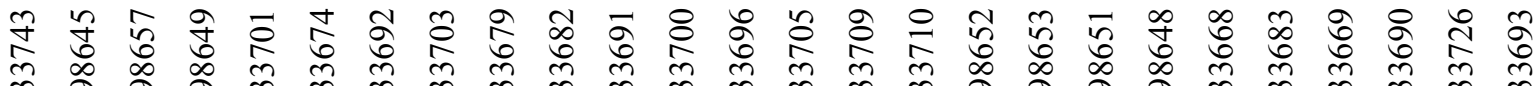

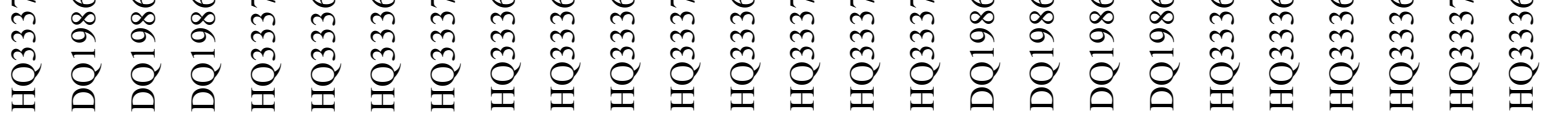

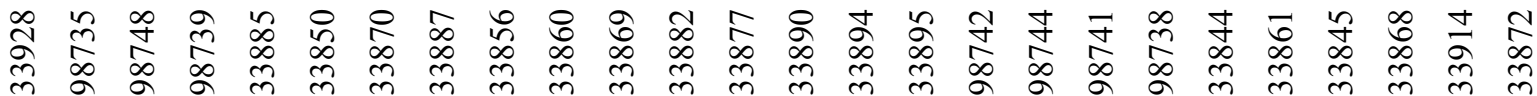

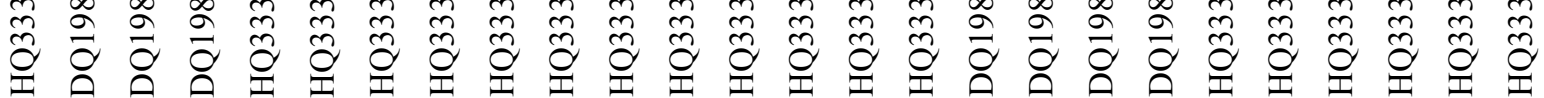

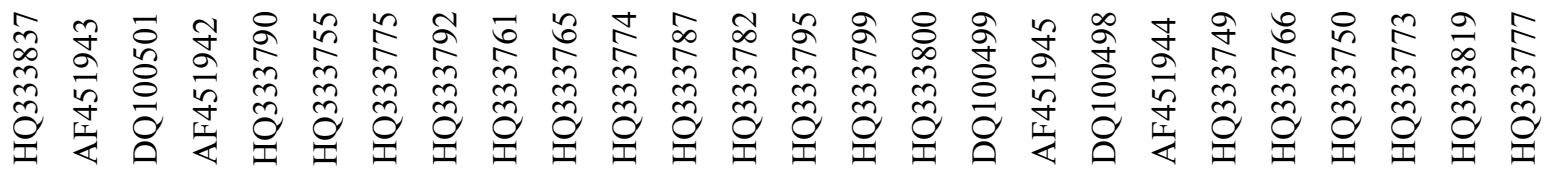

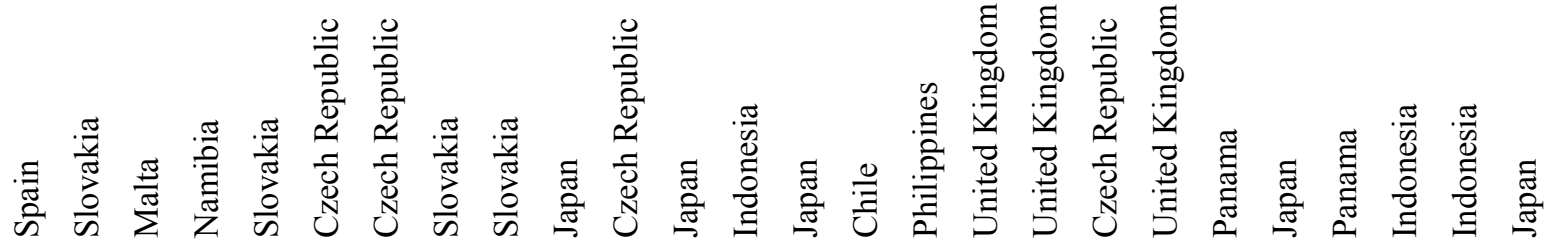

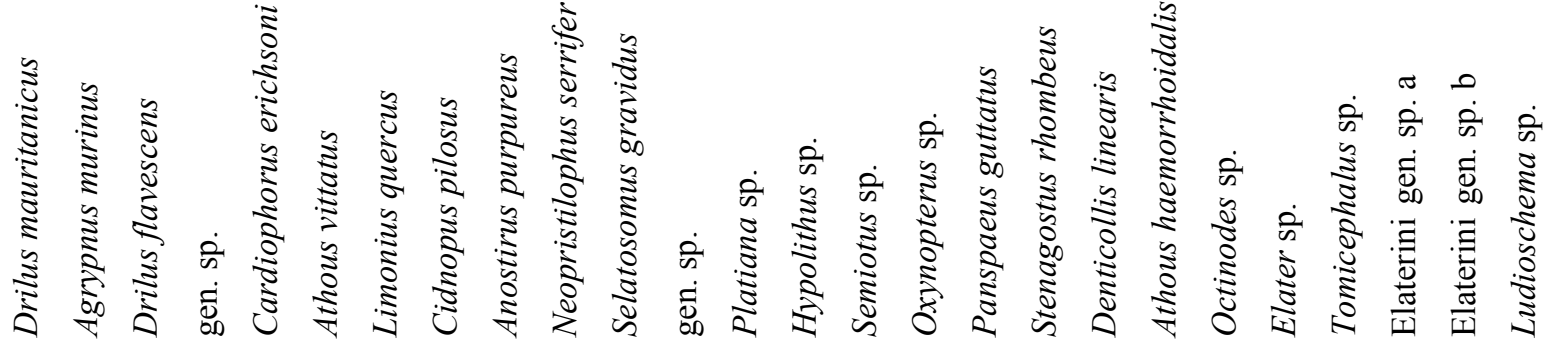

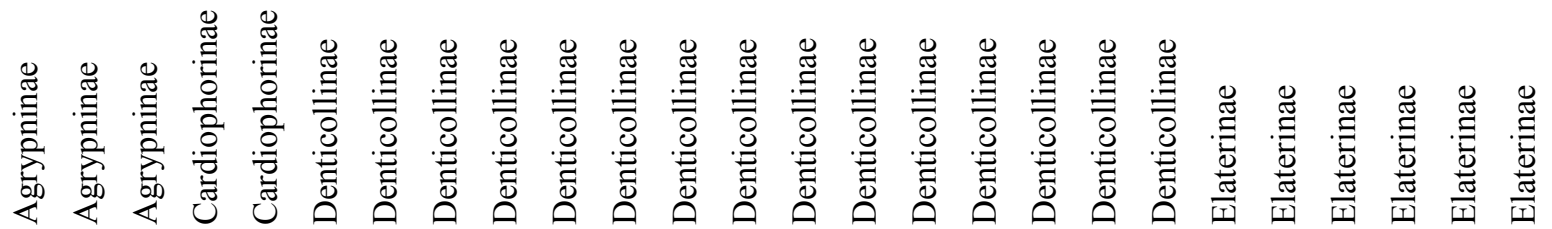

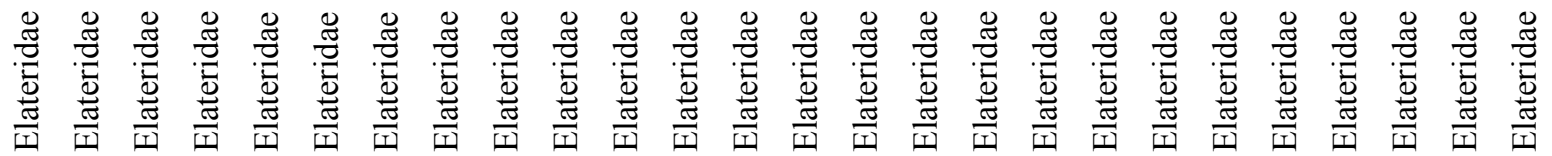




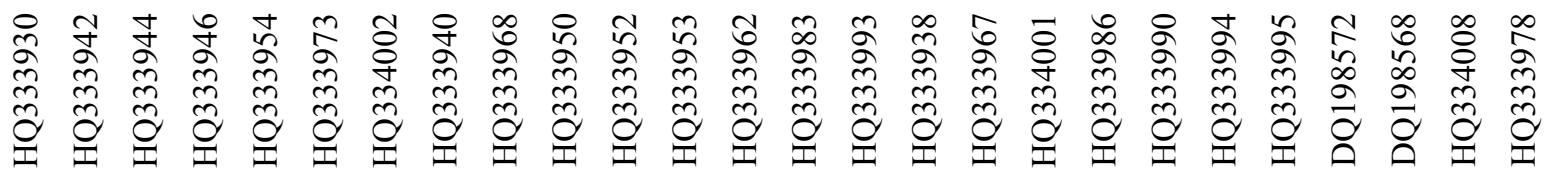

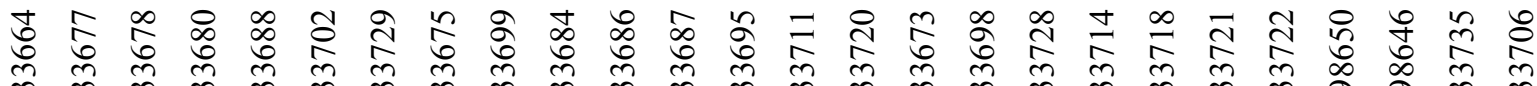

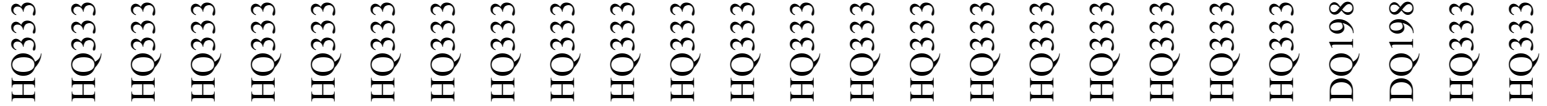

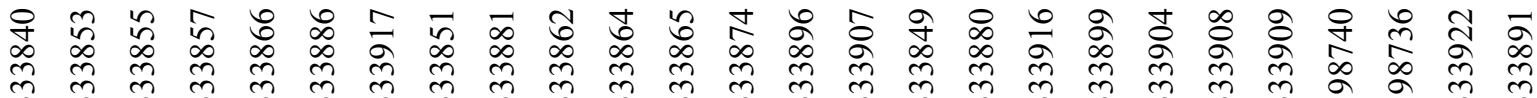

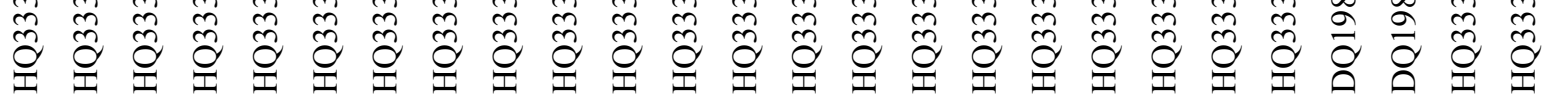

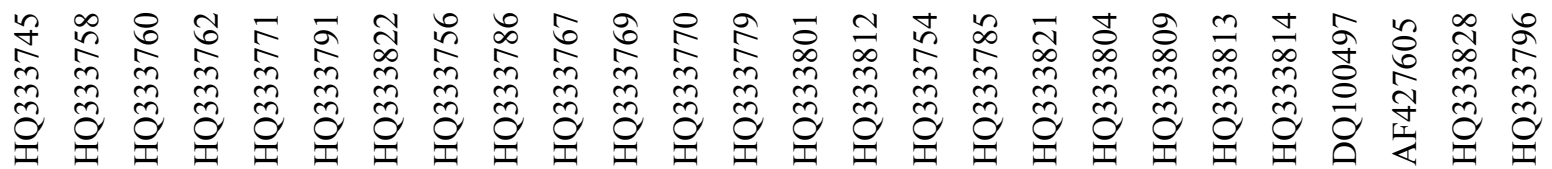

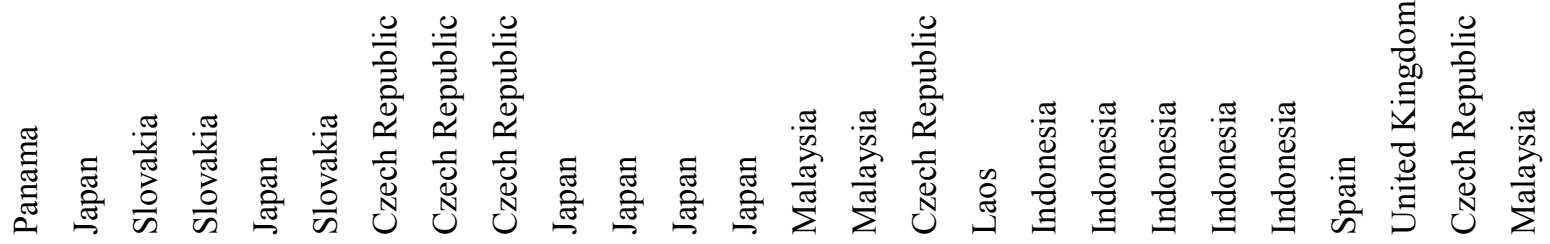

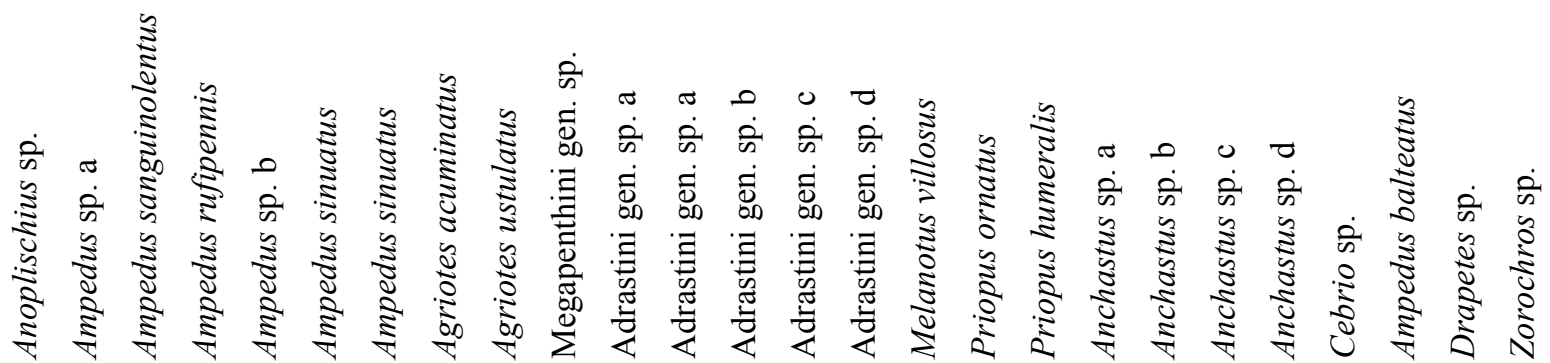

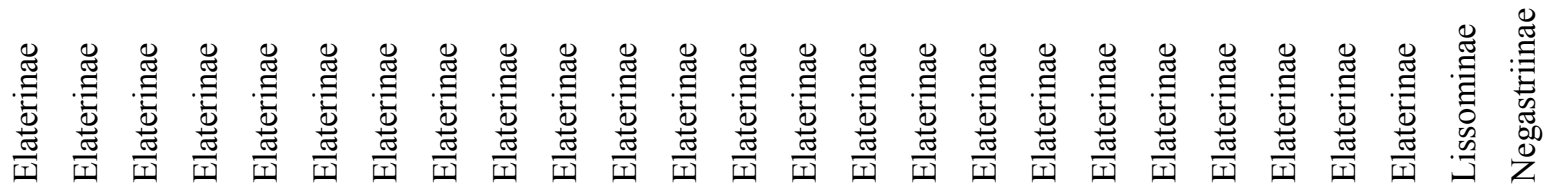

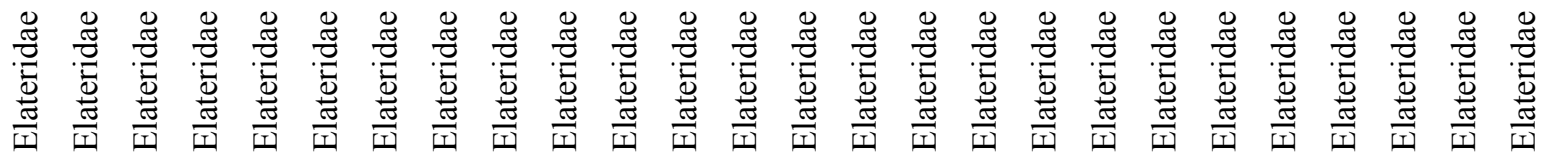




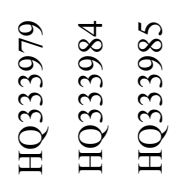

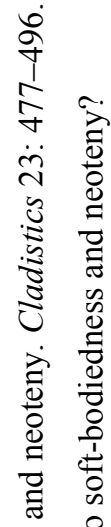

ลे $\hat{\alpha} \stackrel{\infty}{\infty}$

$\hat{} \stackrel{ }{\pi}$

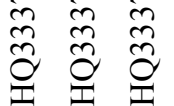

$m m$

호롤호

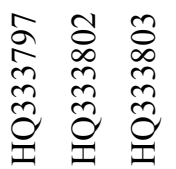

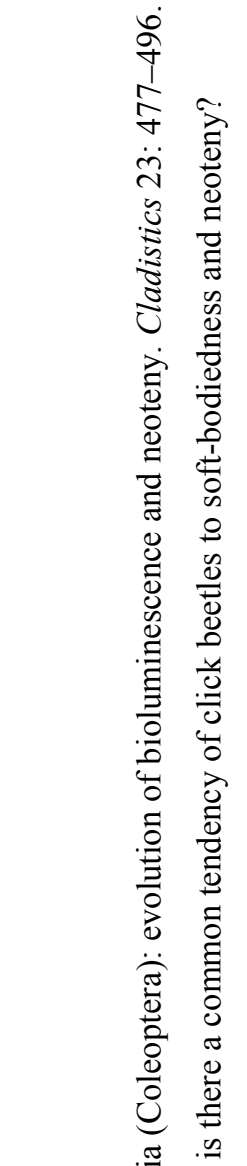

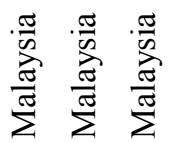

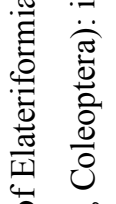

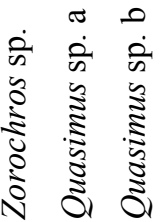

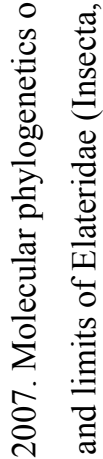

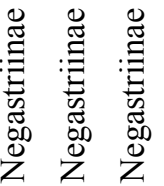

这

$\frac{5}{50}$

if

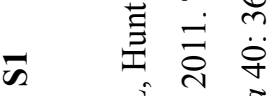

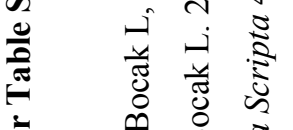

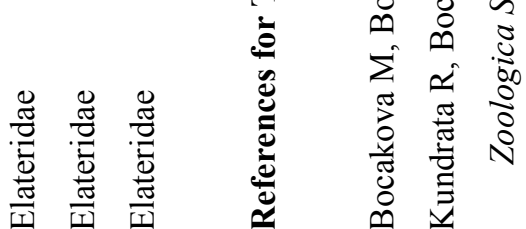




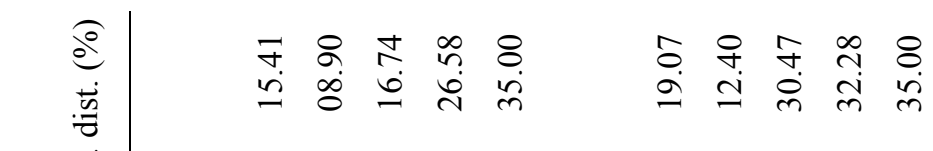

$$
\begin{aligned}
& \text { 递宮 }
\end{aligned}
$$

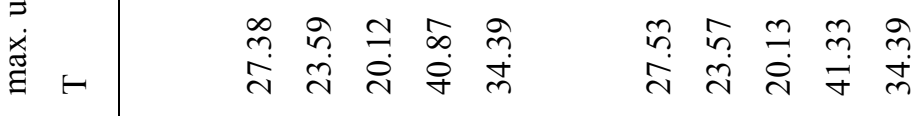

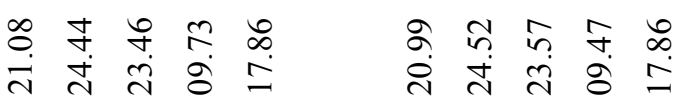

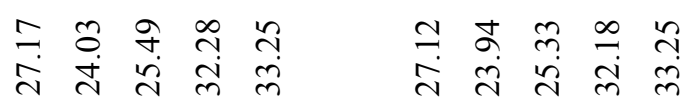

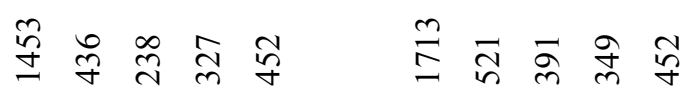

$$
\begin{aligned}
& \text { स }
\end{aligned}
$$

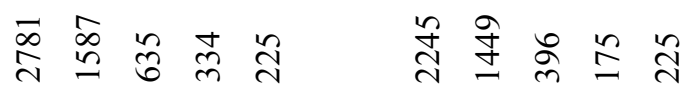

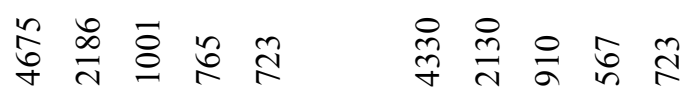

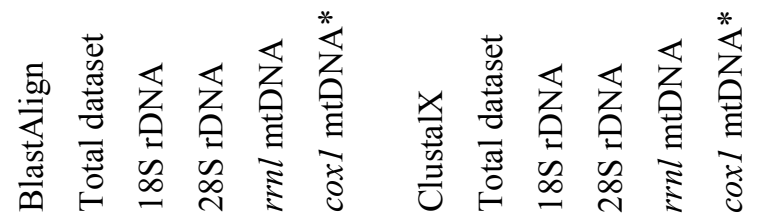




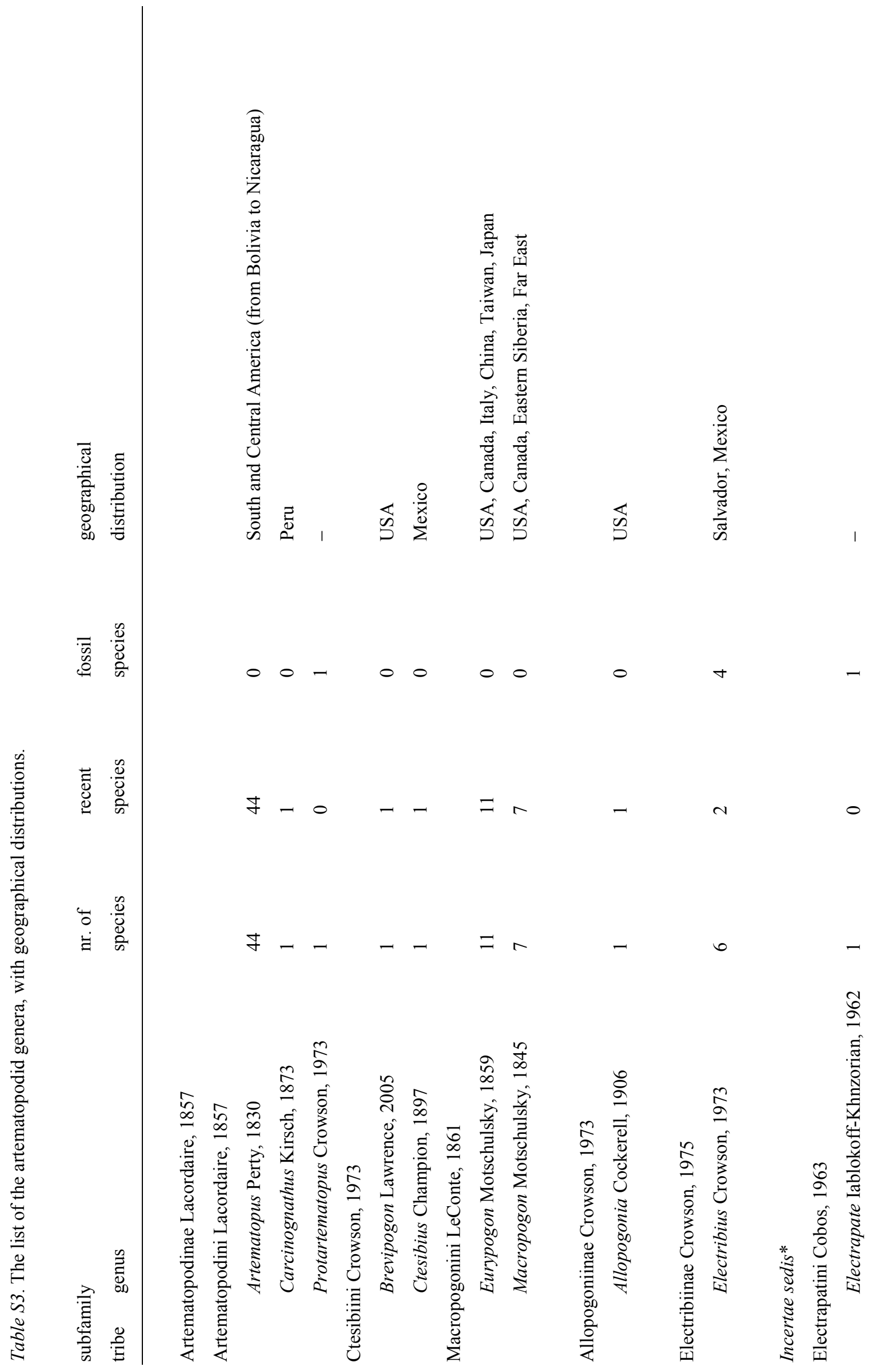




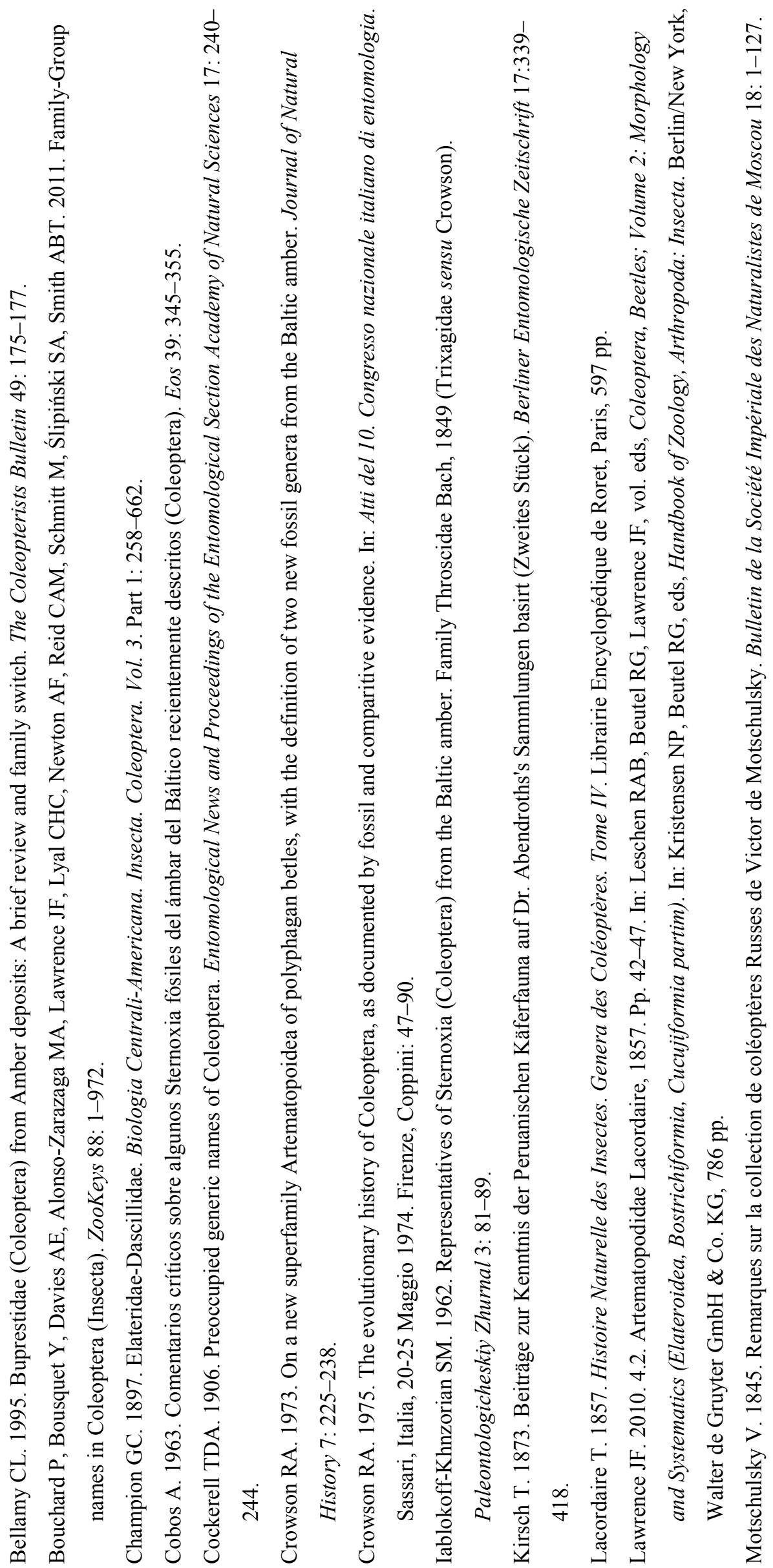




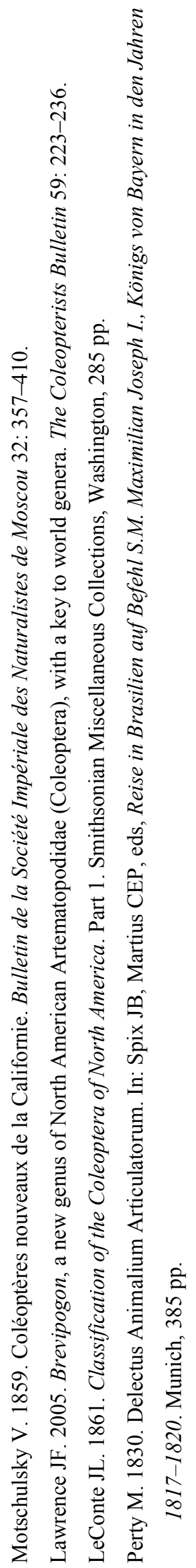




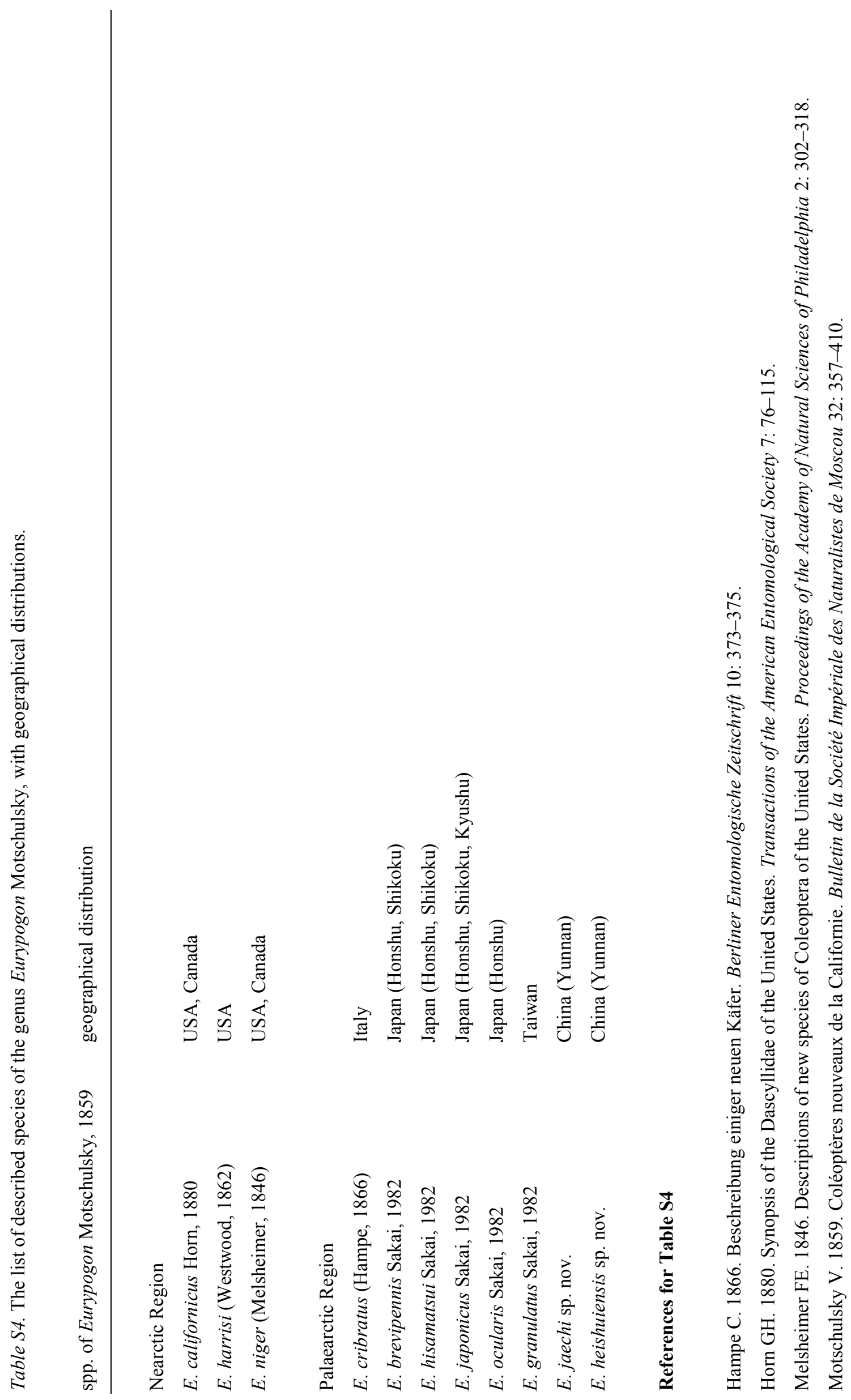




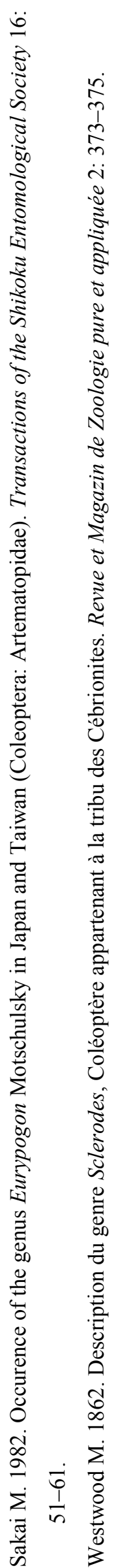

